IZA DP No. 5157

Economic Choices and Status:

Measuring Preferences for Income Rank

Redzo Mujcic

Paul Frijters

August 2010 


\title{
Economic Choices and Status: Measuring Preferences for Income Rank
}

\author{
Redzo Mujcic \\ University of Queensland \\ Paul Frijters \\ University of Queensland \\ and IZA
}

\section{Discussion Paper No. 5157 \\ August 2010}

\author{
IZA \\ P.O. Box 7240 \\ 53072 Bonn \\ Germany \\ Phone: +49-228-3894-0 \\ Fax: +49-228-3894-180 \\ E-mail: iza@iza.org
}

\begin{abstract}
Any opinions expressed here are those of the author(s) and not those of IZA. Research published in this series may include views on policy, but the institute itself takes no institutional policy positions.

The Institute for the Study of Labor (IZA) in Bonn is a local and virtual international research center and a place of communication between science, politics and business. IZA is an independent nonprofit organization supported by Deutsche Post Foundation. The center is associated with the University of Bonn and offers a stimulating research environment through its international network, workshops and conferences, data service, project support, research visits and doctoral program. IZA engages in (i) original and internationally competitive research in all fields of labor economics, (ii) development of policy concepts, and (iii) dissemination of research results and concepts to the interested public.
\end{abstract}

IZA Discussion Papers often represent preliminary work and are circulated to encourage discussion. Citation of such a paper should account for its provisional character. A revised version may be available directly from the author. 


\section{ABSTRACT \\ Economic Choices and Status: Measuring Preferences for Income Rank}

In this paper we report on the trade-offs that 1,068 Australian university students make between absolute income and the rank of that income in hypothetical income distributions. We find that income rank matters independently of absolute income, with greater weight given to rank by males, migrants, and individuals from wealthy families. Rank-sensitive individuals require as much as a 200 per cent increase in income to be compensated for going from the top to the bottom of the income distribution. In terms of reference groups, we find migrants who reside abroad for longer periods of time, and with more affluent job titles, are more likely to compare themselves to others at the destination. This allows us to derive a dynamic choice model of compensating incomes that allows for endogenous tastes and rates of assimilation. The model predicts the average respondent to need a permanent increase in income of up to $\$ 10,000$ when moving from a society with a mean income of $\$ 14,000$ (e.g. Mexico) to a society with a mean income of $\$ 46,000$ (e.g. the USA).

JEL Classification: D03, C91, J61

Keywords: relative utility, status, income rank, stated-preferences, migrants

Corresponding author:

Paul Frijters

University of Queensland

School of Economics

Level 6, Colin Clark Building

St Lucia, Brisbane, Qld 4072

Australia

E-mail: p.frijters@uq.edu.au

\footnotetext{
* We are grateful for helpful comments by Jim Albrecht, Gary S. Becker, Dirk Bethmann, Uwe Dulleck, David Johnston, Arie Kapteyn, Rudolf Kerschbamer, Susan E. Mayer, Xin Meng and Susan Vroman. Any remaining errors are our own.
} 


\section{Introduction}

Status-seeking behaviour is observed in many settings. Whether it be within the family home, school classroom, workplace, local neighbourhood, the discotheque or prison ground, individuals continually compare themselves to others. Economists have formally captured this idea via the concept of relative utility. ${ }^{1}$ Perhaps, the most prominent example of relative utility at play is Richard Easterlin's seminal article (1974) which rationalised the lack of an empirical relation between aggregate happiness and aggregate income by appealing to the notion that people's utility depends on relative income rather than the level of income. This finding has attracted renewed interest in the link between economic choices and social status. Active researchers have proposed status concerns to be able to explain several economic phenomena, including the equity-premium puzzle (Constantinides 1990, Gali 1994); stable labour supply in the face of rising incomes (Neumark and Postlewaite 1998); upward rather than downward sloping wage profiles (Frank and Hutchens 1993, Loewenstein and Sicherman 1991); the feeling of poverty (Sen 1983); the demand for risky activities (Becker et al. 2005); and even migration choices (Stark and Taylor 1991), where someone who is the 'king of a small hill' is unlikely to want to move to the 'foot of a big hill'. ${ }^{2}$ The notion that utility is a function of status, or relative income, entails important consequences for policy design. At the extreme, economic growth becomes no longer important and the progressive taxation of status-seeking is the policymaker's primary obsession (Boskin and Sheshinski 1978, Frank 1985, Layard 1980, 2005).

In the present paper, we consider three questions of empirical nature: First, what is the trade-off between income rank and absolute income in stated-preference choice situations? Second, how long does it take for individuals migrating between societies to begin comparing themselves to the income distribution at the destination, and what does this imply for the trade-off above? Finally, does rank explain choices better than other prominent measures of relative income? We look at these questions with a sample of 1,068 university students from Australia. Our focus on income rank is partially motivated by recent work that finds income rank to be a variable of importance for work effort (Clark et al. 2008b), job satisfaction (Brown et al. 2008), and neighbourhood choice (Clark et al. 2009). ${ }^{3}$

The advantage of using hypothetical choice situations is that it allows one to isolate all non-income factors from the choice situation. Solnick and Hemenway (1998), Johanssson-Stenman et al. (2002), Alpizar et al. (2005), Andersson (2008), and Carlsson et al. (2007, 2009) utilise this idea, and present respondents with imaginary societies which differ in both the absolute and relative income (consumption) domains. ${ }^{4}$ Their results indicate that individuals are willing to exchange absolute income for higher

\footnotetext{
1 See, for example, Friedman and Savage (1948), Duesenberry (1949), Pollak (1976), Kapteyn (1977), Frank (1985), Robson (1992), Hopkins and Kornienko (2004), and Becker et al. (2005).

2 For a recent survey of the literature on relative utility, see Clark et al. (2008a).

3 The importance of rank order for human behaviour has long been recognised by biologists and social scientists, see e.g. Parducci (1963), Layard (1980), Frank (1985), Mayer (1997), Postlewaite (1998), and the references therein.

4 An excellent review of earlier studies is Solnick and Hemenway (1998).
} 
relative income, with the two measures being of similar importance. Choice experiments from these studies share four common features; (i) participants are university students, (ii) the survey design is of written format, (iii) relative income is given in the form of own income divided by the average income in the reference group, and (iv) an entire society forms a reference group. Solnick and Hemenway (1998), Andersson (2008), and Carlsson et al. (2007) are exceptions to (i). In the two former studies, university staff members form a part of the sample, providing greater socioeconomic variation. Carlsson et al. (2007) manage to successfully capture a random sample of the general population by mailing out their questionnaire to residents of Sweden. A departure from features (ii) and (iv) is realised in Carlsson et al. (2009). The study introduces a hypothetical setup of the caste system in India, where a more compact reference group is formed by including a measure of relative standing within one's own cast, in addition to one's society. The authors also employ a graphical (bar chart) representation of the choice situations, deviating somewhat from feature (ii).

We contribute to this literature by strictly deviating from features (ii) and (iii). We introduce a survey instrument of pure graphical construct, where hypothetical societies are described by discrete distributions of income. Similar to earlier studies, we alter the combination of income and status available in each society, and ask respondents to state their preferences. Our approach brings about several advantages. For participants, the task at hand becomes clear as each choice situation is simple to understand and relate to. At the same time, a graphical construct facilitates the simultaneous inclusion of various forms of relative income in addition to the widely used ratio comparison income (feature (iii)). This means our study does not frame the choice situation in terms of absolute level versus rank, but rather allows the respondent to decide what is important about the choice situation.

Our data allow us to estimate a rich preference specification and contains unique information on migrant reference groups. We consider the reference group, i.e. the income distribution an individual relates to, as being endogenous and obtain explicit measures of the amount of time migrants require to substitute the income distribution in the home society for the one at the destination. We incorporate this information into a dynamic choice problem, and estimate the compensating income needed to offset a migrant's loss of status. Overall, in addition to providing new insights into the three questions posed, our study makes data and methodological contributions to the literature on relative preferences.

The rest of the paper is organised as follows. Section 2 outlines the theoretical background. Section 3 describes the choice experiment. Section 4 follows with the descriptive results. Section 5 contains the econometric analysis, where we estimate preference parameters for income rank and absolute income; study migrant reference groups; and calculate compensating incomes for loss of status. Section 6 focuses on the most predictive form of relative income. The final section summarises the findings and concludes. 


\section{Theoretical Background}

Following Frank (1985), Robson (1992), Hopkins and Kornienko (2004), and Becker et al. (2005), we define an individual's status (or relative income) by her rank in the distribution of income. This income rank is usually captured by $R\left(Y_{i}\right) \in[0,1]$, where $R(Y)$ denotes a cumulative density function of income. We consider a utility function of the form:

$$
U_{i}=U\left\langle Y_{i}, R\left(Y_{i}\right)\right\rangle=Y_{i}+b_{i} R_{i}
$$

where $Y_{i}$ is individual $i^{\prime} s$ absolute level of income, and $R_{i}$ represents the ordinal rank of income $Y_{i}$. Our main interest is in estimating the utility weight $0 \leq b_{i} \leq 1$. In the case of $b_{i}=0$, we revert to the neoclassical assumption where utility depends solely upon absolute income. On the other hand, $b_{i}$ $=1$, corresponds to the case where utility is purely a relative concept (dependent on rank order). In the empirical application, $b_{i}$ will be a function of individual characteristics, and the income distribution against which an individual calculates her rank $R_{i}$ will also be endogenous.

In addition to the arguments in utility function (1), we consider other popular measures of relative income, namely: (i) ratio comparison income, $Y_{i} / \bar{Y}$, where individuals are assumed to compare themselves to the average in society, $\bar{Y}$, and (ii) the notion of relative deprivation, defined as the proportion of individuals in $i^{\prime} s$ reference group who are richer than $i$, weighted by their mean excess income (Yitzhaki 1979). We define these measures more formally in Section 6 .

\section{The Choice Experiment}

Employing a graphical stated preference approach, we present respondents with 11 hypothetical choice situations. In each choice situation, respondents are asked to make a choice between two hypothetical countries/societies, A and B. Each society is characterised by an income distribution, made up of 9 hypothetical income earners. These individuals form a reference group. Of the nine individuals, one is pre-selected (highlighted) to represent the imagined respondent. This approach deviates somewhat from existing studies where respondents are made to represent a future relative, such as a grandchild. The idea in those studies being to isolate choice making from any pending life shocks. Although intuitive, it can nevertheless be argued that such a representation draws the decision maker further away from reality. This comes about as survey respondents are made to consider a 'two-dimensional' hypothetical; (i) making hypothetical choices, and (ii) doing so, on behalf of someone who is yet to, or never may, exist. Furthermore, as respondents have quite limited information about the preferences of their imaginary grandchild, they are bound to express their own. To this end, allowing respondents to represent themselves bears no serious limitation, i.e. gains realism.

The hypothetical societies are described by a set of attributes, namely income and positional measures. 
These attributes are varied across choice situations to provide the variation needed to estimate preference parameters. The amount of income each member of society enjoys is made explicit. On the other hand, positional measures, such as income rank, are not. These values are easily inferred upon visual inspection of each choice situation.

The survey consists of two parts. Part A asks respondents a set of socioeconomic questions. A subset of these examines actual reference groups. Part B of the survey contains the 11 choice situations. At the beginning of each session, participants are given verbal information and instructions about the study. Detailed information about the research question(s) is withheld until all responses are complete. By not promoting the general research question ('Does relative standing matter?'), we avoid placing any pressure on participants to make the study a success (or a failure). We simply allow participants to realise the concept independently.

Before recording their preferences, survey respondents read the following instructions:

The following 11 questions ask you to select $\boldsymbol{O N E}$ from two possible options. Based on your preferences, please indicate (by circling either the illustrated individual marked $\Downarrow$ in Country $\boldsymbol{A}$, or the individual marked in Country B) in which 'Country' you would prefer to be in, excluding all other factors.

The annual after-tax income/salary of each individual (measured in Australian dollars) is displayed directly below the illustrated individual. In the two countries, the cost of living is identical.

We next illustrate the constructed choice situations. In choice situations 1 to 6 , we study choices between absolute income and income rank. Choice situations 7,8 and 9, evaluate choices between alternative forms of relative income. There, we examine whether individuals maximise income rank or ratio comparison income. Similarly, the last two choice situations (10 and 11) focus on the trade-off between income rank and relative deprivation.

\subsection{Choice Situations 1 to 6}

In choice situation 1 (Figure 1), the respondent is asked to select between the highlighted income earner in society A (top panel) and the highlighted income earner in society B (bottom panel). Income levels in society A are discretely distributed between $\$ 10,000$ and $\$ 90,000$. The imagined respondent earns an income of $\$ 70,000$ in society $\mathrm{A}$, and is ranked 3rd from the top. In society $\mathrm{B}$, the highest income earner attains $\$ 40,000$ and an income rank of 1 . This corresponds to the imagined respondent. The lowest income level in society B is $\$ 500$. Overall, the respondent faces a choice between a higher absolute level of income (society A) or a higher ordinal rank of income (society B). Are individuals willing to forgo $\$ 30,000$ for 'top-dog' status? 


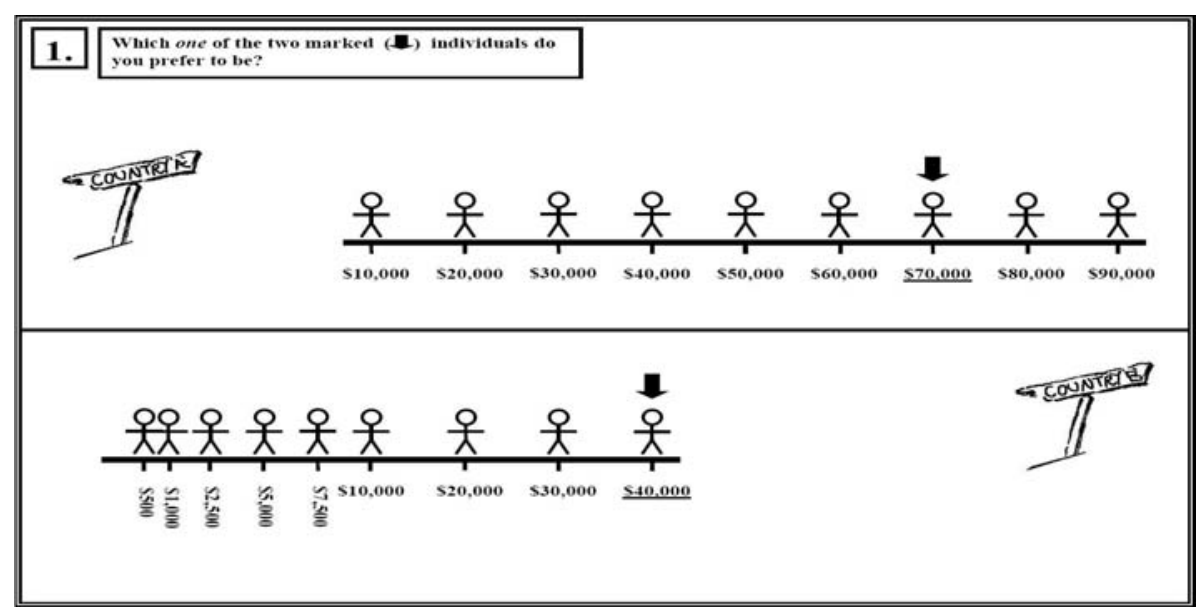

FIG. 1: Choice Situation 1 (Income Rank vs. Absolute Income)

In choice situation 2 (Figure 2), we focus on the lower end of the income distribution. The choice of society A results in own income of $\$ 10,000$ and an income rank of 9, i.e. last place. On the other hand, the choice of society B entails higher status (income rank of 7 ), however a lower level of income $(\$ 2,500)$. By choosing society B, individuals forgo $\$ 7,500$ and climb 2 ranks up from the bottom of society. Similarly, in choice situation 3, we focus on the middle part of the income distribution (see Appendix A1).



FIG. 2: Choice Situation 2 (Income Rank vs. Absolute Income)

In choice situations 4,5 , and 6 , the income gap between the two hypothetical societies is reduced. The income distribution in society A is left unchanged, while that of society B is shifted to the right (Figure 3). The difference between the top incomes is now $\$ 15,000$. Here, the choice is analogous to one faced by a resident of a rich society (A) who is contemplating a move to a slightly less richer society (B). In choice situation 4, a move from society A to B brings about a fall in absolute income of $\$ 5,000$ and a gain in status of one income rank (resulting in 'top-dog' status). Choice situations 5 and 6 allow for the same trade-off, however only for different parts of the income distribution (see Appendix A1). 


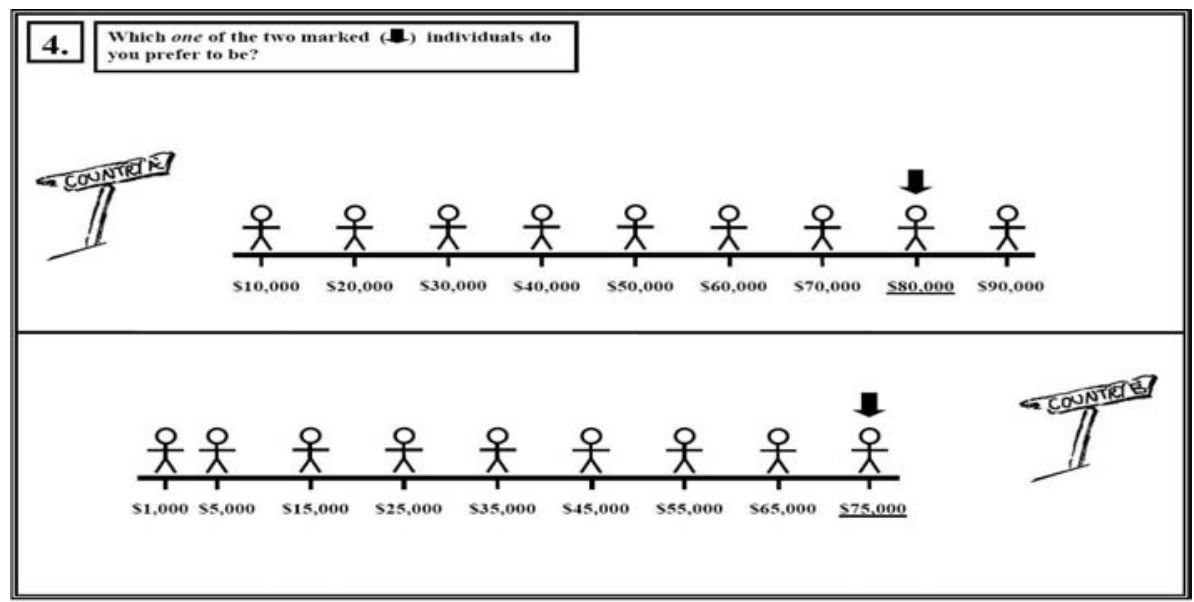

FIG. 3: Choice Situation 4 (Income Rank vs. Absolute Income)

It should be noted that choice situations 1 to 6 are subject to some criticism. Since we present entire distributions of income, survey respondents could potentially be maximising a range of relative income measures, or even measures of inequality. This comes about as none of the relative income measures are held constant across societies. Table 2 contains the actual values of these variables. For instance, in choice situations 1, 4 and 6, society A presents a higher level of absolute income, while society B offers a bundle of more favourable positional measures (i.e. income rank, ratio comparison income, and relative deprivation). Which of the latter three measures is being maximised? To determine this, we set up an econometric 'beauty contest' between the different attributes of these distributions (see Section 6).

\subsection{Choice Situations 7, 8 and 9}

Choice situations 7, 8 and 9 examine choices between income rank and ratio comparison income. Here, the latter measure, along with absolute income, is held constant across the two imaginary societies, while income rank is varied. The intuition is as follows: if income rank is of no importance, conditional on both absolute income and ratio comparison income, we should realise a uniform choice distribution. That is, in a large sample, we would expect an approximate fifty percent chance of either society being selected (i.e. a lottery). Any significant deviation, in favour of the higher rank option, would support rank maximising behaviour (conditional on the other income measures). Figure 4 illustrates choice situation 7 . An income rank of 3 is obtained in society A, and a rank of 2 (second best) in society B. Representations of choice situations 8 and 9 , where we study the bottom and middle parts of the income distribution, are contained in Appendix A1. 


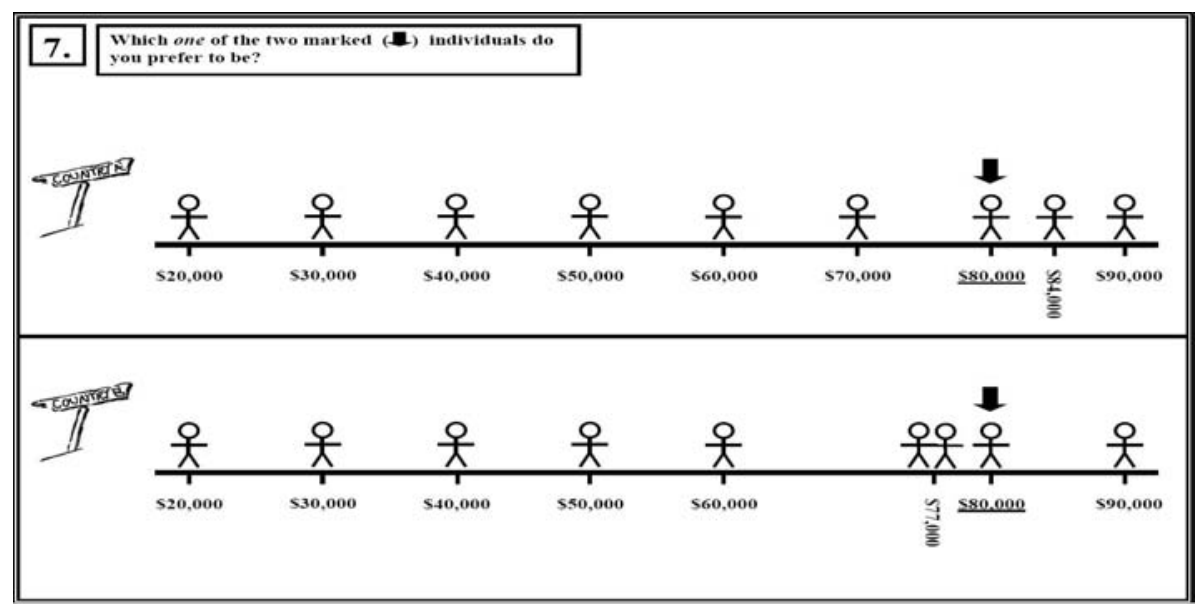

FIG. 4: Choice Situation 7 (Income Rank vs. Ratio Comparison Income)

\subsection{Choice Situations 10 and 11}

In the last two choice situations (cs 10 and 11), we study preferences for income rank and relative deprivation. To obtain a clear result, we keep absolute income and ratio comparison income constant, and offer respondents a more favourable level of only one attribute in each society. In choice situation 10, society A offers a lower (higher) level of relative deprivation (satisfaction) and a lower income rank, relative to society B. Hence, a 'rank maximiser' would prefer society B, while a 'rd minimiser' would favour society A. In choice situation 11, the same trade-off is in place for individuals residing at the bottom end of the income distribution (see Appendix A1).

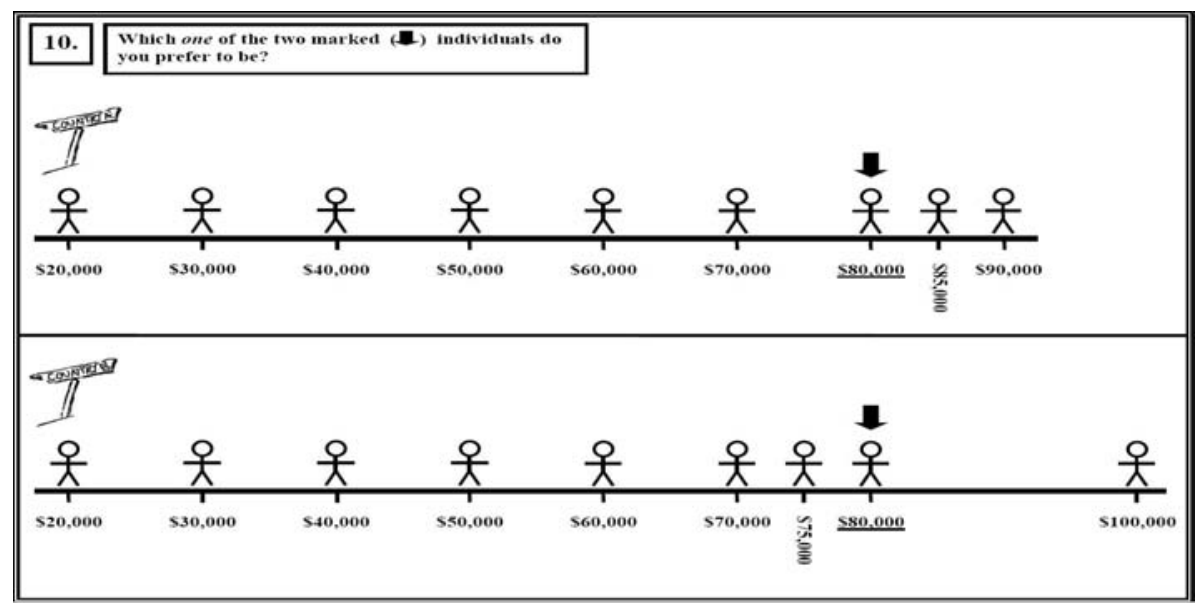

FIG. 5: Choice Situation 10 (Income Rank vs. Relative Deprivation)

In the version of the survey presented above, society B (the bottom panel) may be labelled as 'statusseeker paradise', offering a higher level of status in each choice situation. To minimise potential ordering or systematic choice effects, a second version of the survey was distributed to roughly half (455) of 
the participants. This was a randomised copy of the one presented above (see Appendix A2), where we altered the order of choice situations and randomly assigned the 'country/society' with the more favourable income rank (to the top (A) and bottom (B) panels).

\section{Descriptive Results}

Our sample consists of 1,068 students from the Faculty of Business at the Queensland University of Technology in Brisbane, Australia. The respondents, being university students, were on average young, single, low-income earners from wealthy families (see Table 1). About one-third (315) of the respondents had migrated to Australia from another country. Studying migrants is of interest to us since these individuals may have already experienced, or are likely to experience, similar choice situations in reallife. We split the sample into two groups, migrants and non-migrants, and find that respondents from the former are on average more educated, earn higher incomes, and come from less wealthier families. ${ }^{5}$ In addition, we capture interesting information about reference groups. Two-thirds of the migrants compared themselves, in terms of income level, to family members, friends and colleagues from the destination country (Australia), giving support to reference group substitution.

Table 2 presents response frequencies for each choice situation. ${ }^{6}$ In general, individuals do care about income rank. Of the 11,748 total choices made, 44 percent $(5,169)$ correspond to the society offering a higher income rank. This result is consistent with earlier studies, such as Solnick and Hemenway (1998), where about 50 percent of the respondents selected the society with a more favourable relative income. Responses for the first three choice situations suggest that individuals are willing to pay a non-trivial premium for a higher income rank. As expected, being in last place seems to derive the most disutility with 42 percent of the respondents avoiding society $\mathrm{A}$ in choice situation 2. The proportion of statusseekers broadly increases when we reduce the price of status ( $\operatorname{cs~} 4,5$ and 6$)$. Income rank seems to outperform ratio comparison income (rci) as a measure of status. This is apparent in choice situations 7 and 9 , where 60 per cent of respondents selected the society with a higher income rank. The opposite is true in choice situation 8 , where rci maximising behaviour is evident. In the case of income rank versus relative deprivation (cs 10 and 11), the former measure seems to matter most for low-income individuals (cs 11).

\footnotetext{
${ }^{5}$ See Tables 7 and 8 in Appendix A3.

6 We find no significant differences (at the .05 level) between sample proportions for the choice situations across the two versions of the survey, suggesting the absence of any ordering or systematic choice effects. Hence, we proceed by combining/pooling responses from the two surveys.
} 
TABle 1: VARiable Definitions And Summary Statistics

\begin{tabular}{|c|c|c|c|}
\hline Variable & Description & Mean & Std \\
\hline Age & Years of age & 22.48 & 5.91 \\
\hline Gender & $=1$ if male & 0.46 & 0.50 \\
\hline Partner & $=1$ if have partner & 0.29 & 0.45 \\
\hline \multirow[t]{4}{*}{ Yrs of education } & & 12.66 & 1.07 \\
\hline & $=12$ if completed high school & & \\
\hline & 13 if graduate certificate/diploma & & \\
\hline & 15 if university degree & & \\
\hline Employed & $=1$ if employed & 0.70 & 0.46 \\
\hline \multirow[t]{4}{*}{ Job title } & & 1.12 & 1.00 \\
\hline & $=1$ if low skilled (e.g. cashier) & & \\
\hline & 2 if junior/associate professional (e.g. graduate engineer) & & \\
\hline & 3 if professional (e.g. senior engineer) & & \\
\hline Income & Disposable annual income from all sources ('000 AUD) & 32.10 & 23.38 \\
\hline \multirow[t]{4}{*}{ Family wealth } & Perceived family wealth relative to average Australian family & 3.35 & 0.87 \\
\hline & $\begin{aligned}= & 1 \text { if much poorer } \\
& 2 \text { if somewhat poor } \\
& 3 \text { if as rich }\end{aligned}$ & & \\
\hline & 4 if slightly richer & & \\
\hline & 5 if much richer & & \\
\hline Migrant & $=1$ if migrated to Australia & 0.29 & 0.46 \\
\hline Yrs in Australia (A) & Number of years since arrival to Australia & 5.61 & 5.44 \\
\hline In contact Home $(\mathrm{H})$ & $=1$ if in contact with friends/work colleagues from Home & 0.89 & 0.32 \\
\hline Friends in Australia & $=1$ if formed new friends/work colleagues in Australia & 0.97 & 0.16 \\
\hline Contact, A vs H & $=1$ if more in contact with colleagues in Australia & 0.71 & 0.45 \\
\hline Reference group, A vs H & $=1$ if reference group in Australia & 0.66 & 0.47 \\
\hline
\end{tabular}


TABle 2: Attributes of societies And Response Frequencies

\begin{tabular}{|c|c|c|c|c|c|c|c|c|c|}
\hline $\mathrm{CS}$ & Society & Abs Income & Income Rank & Avg Inc Society & Std Dev Inc & Ratio Comp Income & Rel Dep & Poverty & $\widehat{p}($ Society $)$ \\
\hline \multirow[t]{2}{*}{1} & $\mathrm{~A}$ & $(70,000)$ & 3 & $(50,000)$ & 27,386 & 1.40 & 3,333 & $\begin{array}{l}(0.22) \\
\end{array}$ & 0.78 \\
\hline & B & 40,000 & (1) & 12,944 & $(14,057)$ & $(3.09)$ & (0) & 0.44 & 0.22 \\
\hline \multirow[t]{2}{*}{2} & $\mathrm{~A}$ & $(10,000)$ & 9 & $(50,000)$ & 27,386 & $(0.20)$ & 40,000 & $(0.22)$ & 0.58 \\
\hline & B & 2,500 & (7) & 12,944 & $(14,057)$ & 0.19 & $(10,830)$ & 0.44 & 0.42 \\
\hline \multirow[t]{2}{*}{3} & A & $(40,000)$ & 6 & $(50,000)$ & 27,386 & $(0.80)$ & 16,666 & $(0.22)$ & 0.74 \\
\hline & B & 10,000 & (4) & 12,944 & $(14,057)$ & 0.77 & $(6,666)$ & 0.44 & 0.26 \\
\hline \multirow[t]{2}{*}{4} & A & $(80,000)$ & 2 & $(50,000)$ & 27,386 & 1.60 & 1,111 & $(0.22)$ & 0.61 \\
\hline & B & 75,000 & (1) & 35,667 & $(26,344)$ & $(2.10)$ & (0) & 0.33 & 0.39 \\
\hline \multirow[t]{2}{*}{5} & A & $(10,000)$ & 9 & $(50,000)$ & 27,386 & $(0.20)$ & 40,000 & $(0.22)$ & 0.62 \\
\hline & B & 5,000 & (8) & 35,667 & $(26,344)$ & 0.14 & $(31,111)$ & 0.33 & 0.38 \\
\hline \multirow[t]{2}{*}{6} & A & $(50,000)$ & 5 & $(50,000)$ & 27,386 & 1.00 & 11,111 & $(0.22)$ & 0.64 \\
\hline & B & 45,000 & (4) & 35,667 & $(26,344)$ & $(1.26)$ & $(6,666)$ & 0.33 & 0.36 \\
\hline \multirow[t]{2}{*}{7} & A & 80,000 & 3 & 58,222 & 24,869 & 1.37 & 1,550 & 0.11 & 0.39 \\
\hline & B & 80,000 & (2) & 58,222 & $(24,621)$ & 1.37 & $(1,111)$ & 0.11 & 0.61 \\
\hline \multirow[t]{2}{*}{8} & A & 30,000 & 8 & 52,667 & 23,958 & 0.57 & 23,777 & 0.11 & 0.51 \\
\hline & B & 30,000 & (7) & 52,667 & $(23,701)$ & 0.57 & $(23,333)$ & $(0.00)$ & 0.49 \\
\hline \multirow[t]{2}{*}{9} & A & 60,000 & 5 & 56,000 & 23,108 & 1.07 & 7,111 & 0.11 & 0.38 \\
\hline & B & 60,000 & (4) & 56,000 & $(22,842)$ & 1.07 & $(6,666)$ & 0.11 & 0.62 \\
\hline \multirow[t]{2}{*}{10} & A & 80,000 & 3 & 58,333 & $(25,000)$ & 1.37 & $(1,666)$ & 0.11 & 0.51 \\
\hline & B & 80,000 & (2) & 58,333 & 25,739 & 1.37 & 2,222 & 0.11 & 0.49 \\
\hline \multirow[t]{2}{*}{11} & A & 30,000 & 8 & 52,778 & $(23,863)$ & 0.57 & $(23,777)$ & $(0.11)$ & 0.39 \\
\hline & $\mathrm{B}$ & 30,000 & (7) & 52,778 & 27,055 & 0.57 & 24,444 & 0.22 & 0.61 \\
\hline
\end{tabular}

NoтE: Income Rank is defined as the ordinal rank of own income out of 9 , where $1=$ highest (best) and $9=$ lowest (worst). Ratio Comp Income is calculated by dividing column (3) by column (5). Std Dev Inc is the standard deviation of income in society. Rel Dep is the proportion of individuals who are richer than the imagined respondent, weighted by their mean excess income. Poverty is the proportion of individuals below half of the mean-income in society. Parentheses indicate the society with the more favourable measure.

The last column, $\widehat{p}($ Society), is the proportion of respondents choosing each society. Correlation matrix of choice attributes is presented in Table 9 (Appendix A3). 


\section{Econometric Analysis}

\subsection{Parameter Estimates}

In estimating utility function (1), we consider a random utility model of the form

$$
U_{i t}^{s}=V\left(A_{t}^{s}, X_{i}\right)+\epsilon_{i t}^{s}=a Y_{t}^{s}+b R_{t}^{s}+c X_{i}+\epsilon_{i t}^{s}
$$

where $U_{i t}^{s}$ is the utility individual $i$ derives from society $s=A, B$ in choice situation $t=1,2, \ldots 11$. The observed portion of utility, $V_{i t}^{s}$, is assumed to be a linear-in-parameters function of the vector of choice attributes, $A_{t}^{s}=\left\langle Y_{t}^{s}, R_{t}^{s}\right\rangle$, and a vector of individual characteristics, $X_{i}$. The unobserved portion of utility, $\epsilon_{i t}^{s}$, is included to capture any outside concepts that are brought into the choice experiment by the respondent. These include, for example, inattention by the respondent to the task, pure randomness in the respondent's choices, or other quixotic aspects of the stated-preference choices (see Train 2003, Train and Wilson 2008). Furthermore, preferences for absolute income and income rank are bound to differ across socioeconomic groups. To account for this heterogeneity, we specify the preference parameters, $a$ and $b$, as linear functions of the elements of $X_{i}$. For example, $b=k+d$ Male $_{i}+$ gMigrant $_{i}+h W$ ealt $_{i}$, where $d, g$, and $h$ are the interaction effects of interest.

The probability that respondent $i$ chooses society B in choice situation $t$ is

$$
\begin{aligned}
P_{i t}^{B} & =\operatorname{Prob}\left[U_{i t}^{B}>U_{i t}^{A}\right] \\
& =\operatorname{Prob}\left[\epsilon_{i t}^{A}-\epsilon_{i t}^{B}<V_{i t}^{B}-V_{i t}^{A}\right] \\
& =\operatorname{Prob}\left[\widetilde{\epsilon}_{i t}<a\left(Y_{i t}^{B}-Y_{i t}^{A}\right)+b\left(R_{i t}^{B}-R_{i t}^{A}\right)\right]
\end{aligned}
$$

We estimate $a$ and $b$ using a repeated binary probit model, where $\widetilde{\epsilon}_{i t} \sim N(0,1) .{ }^{7}$ Table 3 reports the maximum likelihood results for different model specifications. ${ }^{8}$ The taste parameter estimates reflect beta coefficients as the choice attributes, absolute income and income rank, are in standardised form. Similarly, socioeconomic characteristics such as age, years of education, income and family wealth level have been rescaled into z-scores, allowing us to make inferences about the relative magnitude of preferences. ${ }^{9}$

Income rank does matter for choice behaviour, however to a smaller degree than absolute income. Consider first the estimates from model (2). There, a rank-sensitive individual (male, migrant, from a wealthy family) values absolute income twice as much as income rank $(a=0.9, b=0.46)$. On the other hand, for the reference individual (female, non-migrant, of average wealth) income rank plays no part in

\footnotetext{
7 To simplify interpretation of the results, we redefine Income Rank as '10 - ordinal income rank' (from Table 2). That is, from here on, the top ranked individual (ordinal rank of 1) has an income rank of 9, and the bottom ranked individual attains an income rank of 1 .

8 A log-linear utility specification was also estimated. However, the fit of the model, based on the value of the likelihood function, was significantly lower. Hence, we do not report the results.

${ }^{9}$ As we are only interested in the relative magnitude and direction of the preference parameters $(a$ and $b)$ in the random utility model, i.e. the marginal utility of choice attributes, we only report the (raw) coefficient estimates (in Table 3 ), and not the marginal effects. For a recent discussion on different approaches to analysing interaction effects of variables in non-linear models; see, for example, Ai and Norton (2004) and Greene (2010).
} 
Table 3: Preference Parameter Estimates for Absolute Income and Income Rank

\begin{tabular}{|c|c|c|c|c|}
\hline Model Specification: & (1) & $(2)$ & $(3)$ & (4) \\
\hline Attribute & Coefficient Est & Coefficient Est & Coefficient Est & Coefficient Est \\
\hline Abs Income & $0.8113(0.000)$ & $0.7981(0.000)$ & $0.7341(0.000)$ & $0.7064(0.000)$ \\
\hline Income Rank & $0.1254(0.000)$ & $-0.0019(0.971)$ & $0.0277(0.719)$ & $0.0138(0.861)$ \\
\hline \multicolumn{5}{|l|}{ Interaction Term } \\
\hline Age $\times$ Abs Income & & & $-0.0506(0.284)$ & $-0.0069(0.898)$ \\
\hline Age $\times$ Income Rank & & & $0.0283(0.502)$ & $0.0549(0.253)$ \\
\hline Male $\times$ Abs Income & & $0.0485(0.546)$ & $0.0593(0.464)$ & $0.0673(0.407)$ \\
\hline Male $\times$ Income Rank & & $0.1580(0.026)$ & $0.1513(0.034)$ & $0.1551(0.030)$ \\
\hline Partner $\times$ Abs Income & & & $0.1316(0.194)$ & $0.1496(0.143)$ \\
\hline Partner $\times$ Income Rank & & & $-0.1371(0.119)$ & $-0.1292(0.144)$ \\
\hline Educ $\times$ Abs Income & & & & $-0.0784(0.100)$ \\
\hline Educ $\times$ Income Rank & & & & $-0.0743(0.079)$ \\
\hline Job Title $\times$ Abs Income & & & $0.0179(0.690)$ & $0.0244(0.594)$ \\
\hline Job Title $\times$ Income Rank & & & $0.0125(0.752)$ & $0.0126(0.754)$ \\
\hline Income $\times$ Abs Income & & & & $-0.0264(0.583)$ \\
\hline Income $\times$ Income Rank & & & & $0.0122(0.775)$ \\
\hline Family Wealth $\times$ Abs Income & & $0.0700(0.082)$ & $0.0659(0.104)$ & $0.0649(0.111)$ \\
\hline Family Wealth $\times$ Income Rank & & $0.1153(0.001)$ & $0.1175(0.001)$ & $0.1140(0.002)$ \\
\hline Migrant $\times$ Abs Income & & $-0.0216(0.806)$ & $-0.0043(0.963)$ & $0.0375(0.692)$ \\
\hline Migrant $\times$ Income Rank & & $0.1864(0.017)$ & $0.1855(0.023)$ & $0.2192(0.009)$ \\
\hline Number of observations: & 11,748 & 11,748 & 11,748 & 11,748 \\
\hline Log-likelihood: & -7757.4 & -7740.5 & -7732.0 & -7729.5 \\
\hline
\end{tabular}

Note: Abs Income, Income Rank, Age, Educ, Income and Family Wealth are in standardised form. Model is estimated using responses for choice situations 1 to 12 . P-values in parentheses.

determining choices, and absolute income is of sole importance $(a=0.8, b=0)$. The latter individual (and tastes) also characterises the average female respondent from our sample.

In a more general specification, such as model (3), the relative taste parameter ratios $(a / b)$ are: 1.15 for a young rank-sensitive individual, and 18.08 for the average female respondent, where the former agent has similar preferences for income and status, and the latter is purely interested in her material welfare. ${ }^{10}$

Estimates of the interaction effects suggest that income rank becomes more important as family wealth rises. This is consistent with Veblen's (1899) theory of conspicuous consumption and leisure, where he describes the rich as primarily engaging in activities that display their status, such as via the purchase of luxurious homes or spending time on activities that have no productive purpose, as opposed to the less rich individuals who have to spend more time on productive activities. ${ }^{11}$

The coefficient for the interaction between males and income rank is positive and significant meaning

\footnotetext{
${ }^{10}$ Individual types, their characteristics and preferences are summarised in Table 10 in Appendix A3.

11 In contrast, a recent study using the European Social Survey (Clark and Senik 2010) finds income comparisons being more prevalent amongst the poor.
} 
that the males in our sample care more about rank than females. This finding fits the arguments of Frank (1999) who explains the tendency in males to seek status as possibly having evolved from the once popular practise of polygamous marriage arrangements, where the highest ranked male had the greatest number of off-spring. However, our finding contradicts that by Johanssson-Stenman et al. (2002) and Alpizar et al. (2005), who surprisingly find females to be more status oriented in choice situations where the respondent has to choose between bundles of numeric absolute and relative incomes. Nonetheless, the result is supported by Carlsson et al. (2009).

A significant difference in tastes for rank order is also apparent between migrant and non-migrant groups suggesting that those who migrate do so partially in order to increase their social status. This contrasts with neoclassical models of labour migration, where absolute income differentials are the main determinants of migration streams. From these models, one would expect that, for example, Mexican migrants move to the USA only for the higher absolute wealth and ignore any relative income effects. However, Stark and Taylor (1991), amongst others, find the top income earners within a neighbourhood, village or country to have a lower propensity to migrate. This makes sense within our findings as rankmaximising behaviour implies that those individuals at the top in the sending distribution have more rank to lose than those at the bottom.

Given the differences between survey instruments and empirical methodologies, we are unable to directly compare our results to those in earlier studies. In general, however, students in Australia seem to care about relative standing to a similar degree as students, or respondents, in the USA (Solnick and Hemenway 1998) and Sweden (Johansson-Stenman et al. 2002; Carlsson et al. 2007). Furthermore, the apparent importance of income rank for choice behaviour is consistent with the findings in Brown et al. (2008) and Clark et al. (2009), where the authors find a positive and significant effect of a higher income rank on economic satisfaction.

\subsection{Compensating Income for Loss of Status: The Static Model}

In this section we estimate the income required to compensate an individual who experiences a loss of status. We develop a static choice problem where an individual moving between two societies, or neighbourhoods, fails to experience a fall in her utility level, when the two societies are characterised by different income distributions. That is, we estimate the amount of income that an individual needs to receive after moving from a poor to a rich society, where in the latter her income rank is reduced. We have the following static problem:

$$
U\left\langle Y_{h}, R_{h}\left(Y_{h}\right)\right\rangle=U\left\langle Y_{d}, R_{d}\left(Y_{h}\right)\right\rangle
$$

where the subscripts $h$ and $d$ denote the society at home and the destination respectively; $R_{h}\left(Y_{h}\right)$ is the ordinal rank of income level $Y_{h}$ in the income distribution at home; and $R_{d}\left(Y_{h}\right)$ is the ordinal rank of 
$Y_{h}$ in the income distribution at the destination, where by construct $R_{h}\left(Y_{h}\right)>R_{d}\left(Y_{h}\right)$. We assume the individual to assimilate, and compare to others, at the destination instantaneously. As this is a quite strong behavioural assumption, we later study the case where migrants take some time to substitute reference groups, and hence do not experience the entire fall in status upon arrival. It should be noted that heterogeneity enters the model via: (i) preferences for income and rank, from probit model (3) reported in Table 3, and (ii) initial incomes and positions within the home distribution.

We continue the above example of migratory behaviour between Mexico (home, poor) and the USA (destination, rich), and describe incomes in each society using a lognormal distribution, denoted $L N\left(\mu, \sigma^{2}\right)$. Formally, a lognormal variable $y$ has

$$
\begin{aligned}
E[y] & =e^{\mu+\sigma^{2} / 2} \\
\operatorname{Var}[y] & =e^{2 \mu+\sigma^{2}}\left(e^{\sigma^{2}}-1\right)
\end{aligned}
$$

and the Gini coefficient is defined as

$$
G=2[\Phi(\sigma / \sqrt{2})]-1
$$

where $\Phi$ is the cumulative normal density function (see Aitchison and Brown 1957). Consequently, the parameters $\mu$ and $\sigma$ can be determined from the mean, $E[y]$, and the Gini coefficient, $G$, as follows:

$$
\begin{aligned}
\sigma & =\sqrt{2}\left[\Phi^{-1}\left(\frac{G+1}{2}\right)\right] \\
\mu & =\ln (E[y])-\sigma^{2} / 2
\end{aligned}
$$

We obtain the parameters $\mu$ and $\sigma$ of the lognormal income distribution in each country by substituting recorded values of output per capita, $E[y]$, and the Gini coefficient, $G$, into (8) and (9) above. Real GDP per capita in Mexico and the USA is $\$ 14,400$ and $\$ 46,600$ respectively, and the corresponding Gini coefficent values are 0.47 and 0.38 (OECD.Stat 2010). Thus, we model incomes at home (Mexico) and the destination (USA) as $Y_{h} \sim L N(9.18,0.79)$ and $Y_{d} \sim L N(10.5,0.49)$.

Figure 6 presents the solution to the static choice problem for four different individuals. The general estimates suggest that individuals residing in the bottom and middle parts of the home income distribution are required to be compensated quite a bit more than the elites, in order to be equally well-off in both societies. This results from the former group enduring a greater loss of status at the destination. The reference individual requires the least amount of monetary compensation due to the low utility importance assigned to status. As expected, rank-sensitive individuals require the highest compensatory income given their strong preferences for rank. A young rank-sensitive individual, earning an annual income of $\$ 14,000$ in Mexico, requires a permanent increase in income of $\$ 30,000$ in the USA. Similarly, the average male respondent requires an approximate permanent increase in income of $\$ 20,000$. 


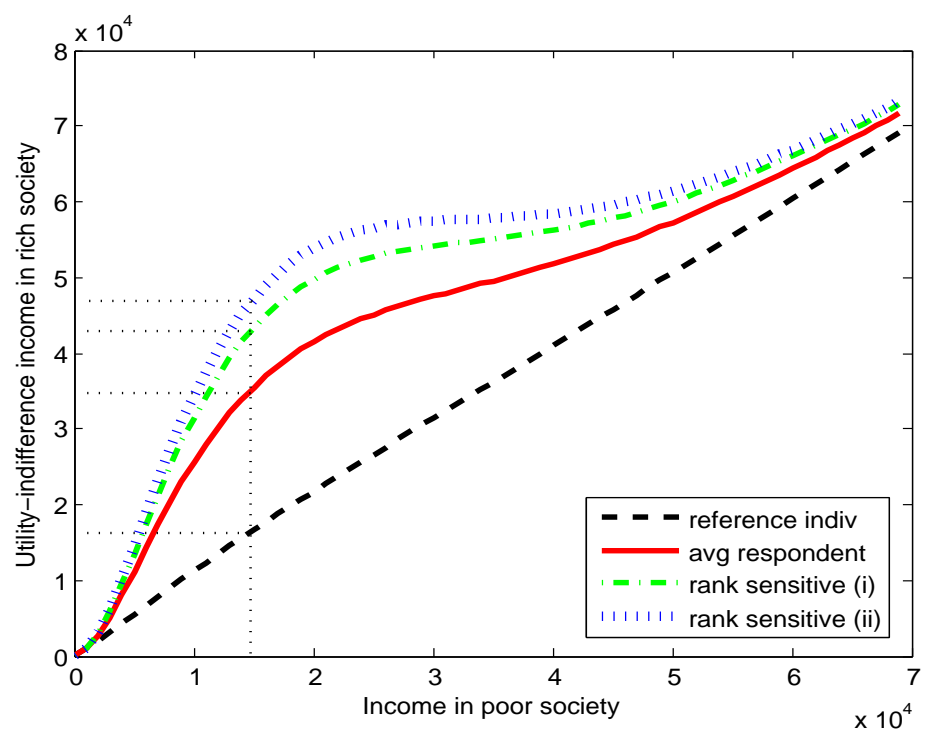

FIG. 6: Compensating Income for Loss of Status (Static Model)

\subsection{Migrant Reference Groups}

A novel part of the data set collected is the information on migrant reference groups. Migrants were explicitly asked whether they compared themselves, in terms of income level, to others in their home country or in the country they currently reside:

In terms of personal achievement (such as Income), which of the two groups, would you say, you compare yourself to? (a) From Australia (b) From Home Country.

Two-thirds of migrant respondents compared themselves to family members, friends, and colleagues in the latter society, indicating the presence of reference group substitution. A key determinant of this reference group substitution is the length of time away from home. We observe the mean value of this variable to be 5.6 years, with 12 percent of the migrants having arrived in Australia less than 1 year ago; 50 percent between 1 and 5 years; 22 percent between 6 and 10 years; 14 percent between 11 and 20 years; and 2 percent arrived more than 20 years ago.

To find out more, we analyse the effects of 'time away from home', and other migrant characteristics, on the probability of reference group substitution. The binary response variable, $y_{i}$, is set to 1 if individual $i$ compares to others in the society abroad (i.e. Australia), and $y_{i}=0$ if the individual relates to others in the home society. Here, we interpret $y_{i}=1$ as migrant reference group substitution or, in other words, complete assimilation.

Table 4 presents the binary logit coefficient estimates. 'Time away from home' seems to be an important determinant of reference group substitution. The positive coefficient suggests that the more time migrants spend away from home, the more likely they are to form peer groups at the destination. Gender, 
relationship status, and family wealth play no part in determining reference groups. The age characteristic is statistically insignificant at the 10 percent level, nevertheless the corresponding coefficient intuitively suggests that young migrants adapt better to new cultures and surroundings relative to the elder. Not surprisingly, migrants with more prominent job titles alter their reference groups more frequently. These individuals are employed as white-collar managers, supervisors and senior professionals, taking on high levels of responsibility and interest in their workplace. One feature of such positions is the presence of large social networks, making it less difficult to form new friends and work colleagues. Moreover, these individuals may be choosing reference groups based on their comparative advantage in obtaining high status (see Frank 1985).

\begin{tabular}{lr} 
TABle 4: Migrant Reference Group Substitution \\
\hline \hline Variable & Coefficient Est \\
\hline Constant & $1.391(0.168)$ \\
Age & $-0.060(0.101)$ \\
Gender & $-0.148(0.633)$ \\
Partner & $0.091(0.814)$ \\
Family wealth & $-0.140(0.403)$ \\
Job title & $0.574(0.005)$ \\
Time away from home (yrs) & $0.227(0.000)$ \\
\hline Number of observations: 249 & \\
Log-likelihood: -126.4 & \\
\hline \hline & \\
Note: Dependent variable equals 1 if individual compares to \\
others at destination, and 0 otherwise. P-values in parentheses.
\end{tabular}

Figure 7 shows the degree of assimilation for different migrant types, who are of similar characteristics as the individuals studied in the static problem above (Section 5.2). Migrants seem to require a period of approximately 25 years to completely assimilate at the destination. The effect that a higher job title (or education level) and age have on the initial propensity to assimilate is evident: Rank-sensitive individual (i)'s superior job title translates into a 0.15 higher initial probability of assimilation relative to the average respondent. The same individual type has a 0.25 probability advantage over rank-sensitive individual (ii), where the latter agent is 17 years older than the former. 


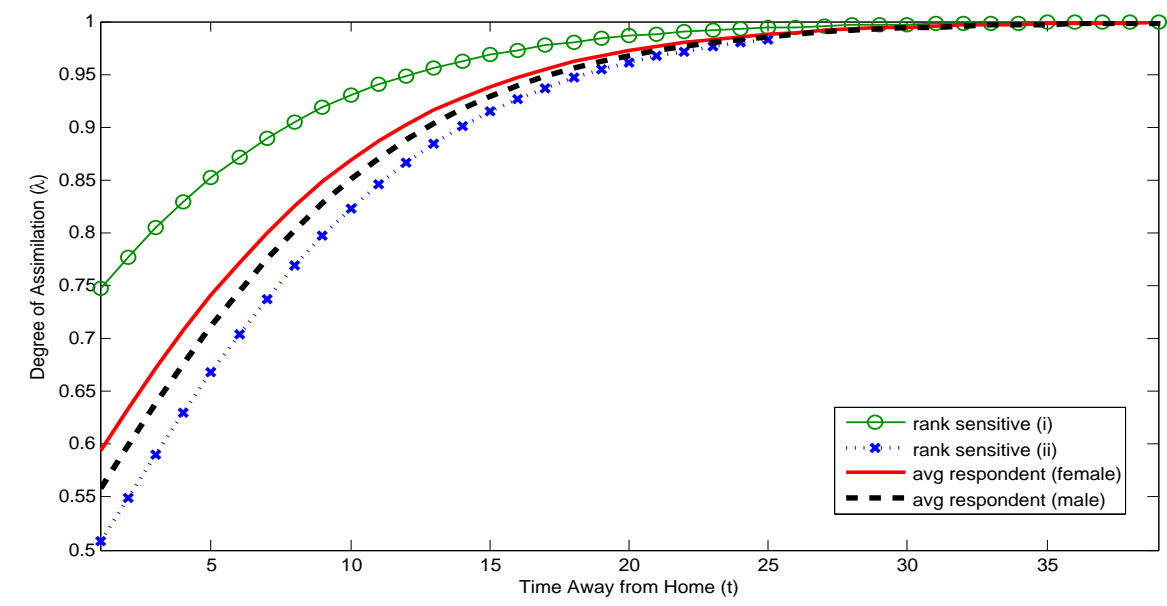

FIG. 7: Degree of Migrant Assimilation over Time

\subsubsection{Compensating Income for Loss of Status with Endogenous Assimilation}

We use the above assimilation model to derive the dynamic form of compensating incomes for migrants who, by construct, endure a loss of status at the destination. The notion that reference group substitution takes time is included in the model by allowing the importance of a lower income rank abroad (in period $t$ ) to be determined by the degree of assimilation (in period $t$ ). Thereby, low status is not realised immediately upon arrival. Instead, its importance gradually increases with the length of time away from home. The degree of assimilation, after $t$ periods, is estimated using the logit probability model from Table 4. We do so for different migrant types, while keeping in mind that the 'time away from home' and 'age' characteristics increase with $t$. We have the following programming problem:

$$
\sum_{t=1}^{T_{i}} e^{-\rho t}\left[U_{i t}\left\langle Y_{h}, R_{h}\left(Y_{h}\right)\right\rangle\right]=\sum_{t=1}^{T_{i}} e^{-\rho t}\left[U_{i t}\left\langle Y_{d}, R_{d}\left(Y_{d}\right)\right\rangle \lambda_{i t}+U_{i t}\left\langle Y_{d}, R_{h}\left(Y_{d}\right)\right\rangle\left(1-\lambda_{i t}\right)\right]
$$

where $T_{i}-t$ is the number of years that individual $i$ still has to live, $\rho$ is the discount rate for future years, and $0 \leq \lambda_{i t} \leq 1$ is the degree to which $i$ has assimilated into the society at the destination. Individual $i^{\prime} s$ status consists of two parts: (i) rank at the destination $R_{d}\left(Y_{d}\right)$, and (ii) rank of the destination income back home $R_{h}\left(Y_{d}\right)$. The relative weight assigned to each component of status changes in each time period as the individual gradually assimilates at the destination and changes reference groups, i.e. $\lambda_{i t} \rightarrow 1$.

The idea behind this approach is to ask an individual who is contemplating to migrate in period 1 , and is fully aware of the dynamic changes in the utility function, how high her income would have to be (until death) for her to have the same discounted utility abroad as in the situation with no possible migration. To determine this amount, we return to the previously defined income distributions of Mexico (home, poor) and the USA (destination, rich), and search ordered pairs of incomes $\left(Y_{d}, Y_{h}\right)$ for which equality (10) holds. This dynamic choice model includes three types of heterogeneity: (i) preferences 
for income and status, (ii) degree of assimilation over time, and (iii) initial incomes and positions in the home income distribution. We set $T_{i}=65-A g e_{i}$, i.e., the migrant is assumed to endure the given loss of status until the age of 65 (end of a working life). The calculations are done for an annual discount rate $\rho$ of 5 per cent.

Figure 8 presents the solution to (10) for different migrant types. As in the static case, migrants who occupy the bottom-half of the income distribution in the poor society require the highest monetary compensation at the destination. The permanent increase in income required for a rank-sensitive individual, who is not amongst the elite, is approximately $\$ 15,000$. For elite migrants, the compensatory income is approximately half of the latter amount $(\$ 7,500)$ due to these individuals not experiencing as much of a fall in income rank. Even though the average female respondent assimilates into the richer society at a relatively high rate, the low utility weight attached to status results in her demanding a low level of monetary compensation. On the other hand, a male average respondent, who considers status to be important, requires a permanent increase in income of approximately $\$ 10,000$.

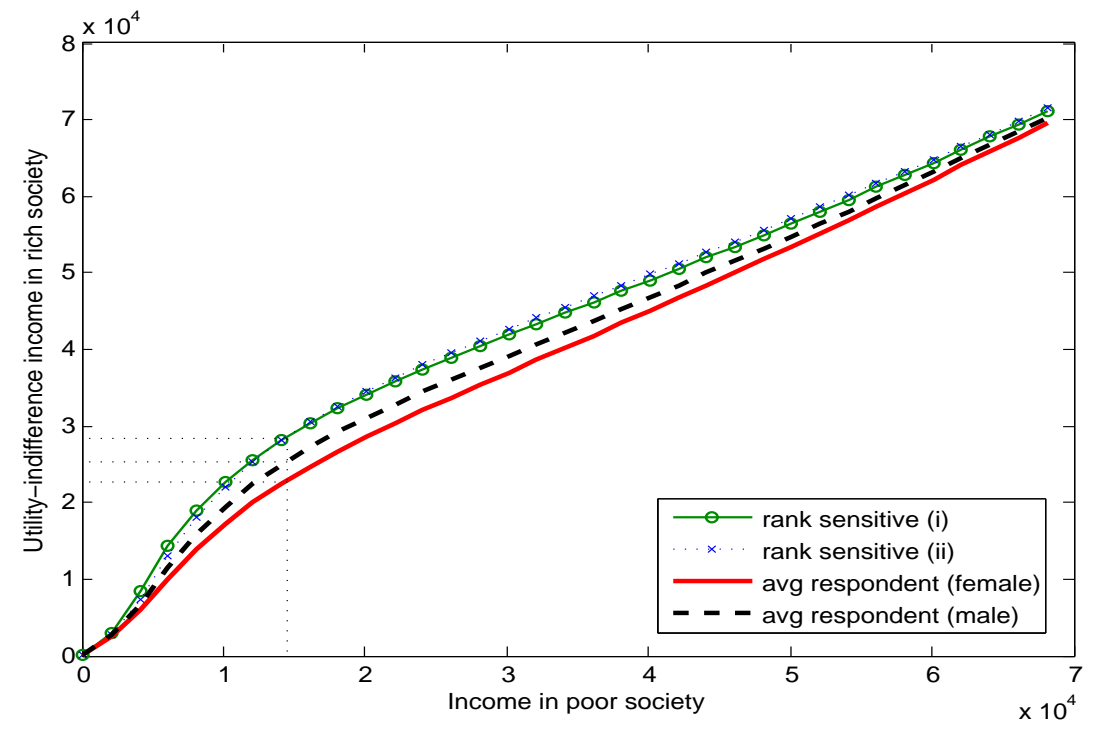

FIG. 8: Compensating Income for Loss of Status with Endogenous Assimilation 


\section{A 'Relative' Beauty Contest}

What form of relative income do individuals maximise? Do individuals really care about some form of relative income, or about entirely different aspects of the hypothesised income distributions, such as the degree of inequality or the poverty rate? These are important, however very much neglected, questions within the relative utility literature. The importance of the issue arises from the proposition that choice behaviour and social welfare are set to differ under the alternative measures of relative income; see, for example, Layard (1980, 2005), Hopkins and Kornienko (2004), Stark and Wang (2005), and Bilancini and Boncinelli (2008).

In many studies, relative income is expressed as ratio comparison income, $Y_{i} / \bar{Y}$, where individuals are assumed to compare themselves to the average in society, $\bar{Y}$. There, status and utility are determined by how much higher or lower $Y_{i}$ is relative to $\bar{Y}$. Another popular measure of relative income is drawn from sociology. Runciman (1966) assumes that people compare themselves with others, and feel relatively deprived when others have what they desire. This form of social comparison has been included in economic models of income inequality (Yitzhaki 1979) and labour migration (Stark and Taylor 1991). In these studies, relative deprivation is defined as the proportion of individuals in $i^{\prime} s$ reference group who are richer than $i$, weighted by their mean excess income:

$$
R D_{i}=\left(1-R\left(Y_{i}\right)\right) E\left(Y_{-i}-Y_{i} \mid Y_{-i}>Y_{i}\right)
$$

where $R(Y) \in[0,1]$ denotes a cumulative density function of income.

We ascertain which of the above measures accounts for the data better by predicting the observed choices using different combinations of income measures and then comparing the resulting log-likelihood values. $^{12}$ In addition to the absolute and relative income measures discussed so far, we include two measures of income inequality: (i) standard deviation of income in society, and (ii) a poverty measure, defined as the proportion of individuals below half of the mean-income in society.

Table 5 reports the values of log-likelihood functions from the estimated binary probit models. The highest log-likelihood is realised in Model 1, where absolute income and income rank are the two choice attributes. A near identical log-likelihood value is obtained by estimating Model 2, where the more popular relative income measure, ratio comparison income, is used. The two measures of income inequality perform relatively well in explaining choices, occupying positions 4 and 5 . Overall, we can conclude that rank is the best fitting measure of relative income, however the difference in predictive ability between

\footnotetext{
12 An alternative would be to try and estimate a structural model with all the income concepts included at the same time. This approach gives rise to collinearity issues as each relative income measures is a function on income. For example, 98 per cent of the variation in absolute income in our data is explained by the variation in income rank, relative deprivation, and average income in society, making estimates of models with many income constructs nonsensical. This issue is, unfortunately, almost unavoidable. In order to get more independent variation between the different income concepts, one would have to resort to using unrealistic distributions (such as a binary distribution) in which case the question arises whether respondents would be able to envisage what such a society would be like. We hence face a trade-off between realism and the ability (ex-post) to separately identify the contribution of each income concept.
} 
rank and ratio comparison income is trivial.

Table 5: A 'Relative' Beauty Contest

\begin{tabular}{|c|c|c|}
\hline Model & Attributes & Log-Likelihood \\
\hline \multirow[t]{2}{*}{1} & Abs Income & \\
\hline & Income Rank & -7757.44 \\
\hline \multirow[t]{2}{*}{2} & Abs Income & \\
\hline & Ratio Comp Income & -7757.48 \\
\hline \multirow[t]{2}{*}{3} & Abs Income & \\
\hline & Rel Deprivation & -7762.22 \\
\hline \multirow[t]{2}{*}{4} & Abs Income & \\
\hline & Std Dev of Income & -7763.68 \\
\hline \multirow[t]{2}{*}{5} & Abs Income & \\
\hline & Poverty Measure & -7763.25 \\
\hline \multirow[t]{2}{*}{6} & Income Rank & \\
\hline & Ratio Comp Income & -7876.34 \\
\hline \multirow[t]{2}{*}{7} & Income Rank & \\
\hline & Rel Deprivation & -7966.36 \\
\hline \multirow[t]{2}{*}{8} & Income Rank & \\
\hline & Std Dev of Income & -7840.23 \\
\hline \multirow[t]{2}{*}{9} & Income Rank & \\
\hline & Poverty Measure & -7872.33 \\
\hline \multirow[t]{2}{*}{10} & Ratio Comp Income & \\
\hline & Rel Deprivation & -7837.97 \\
\hline \multirow[t]{2}{*}{11} & Ratio Comp Income & \\
\hline & Std Dev of Income & -7794.71 \\
\hline \multirow[t]{2}{*}{12} & Ratio Comp Income & \\
\hline & Poverty Measure & -7819.75 \\
\hline \multirow[t]{2}{*}{13} & Rel Deprivation & \\
\hline & Std Dev of Income & -7820.14 \\
\hline \multirow[t]{2}{*}{14} & Rel Deprivation & \\
\hline & Poverty Measure & -7867.78 \\
\hline \multirow[t]{2}{*}{15} & Std Dev of Income & \\
\hline & Poverty Measure & -7825.41 \\
\hline Number of observations: & 11,748 & \\
\hline
\end{tabular}




\section{Conclusion}

This paper used a novel survey instrument to study the choice behaviour of Australian university students over the respondent's ranking in a hypothetical income distribution. The main interests concerned: (i) the utility importance of income rank relative to absolute income, (ii) the endogeneity of migrant reference groups, and (iii) the most predictive form of relative income.

We find that income rank matters relative to absolute income, where the preference parameter is estimated to be higher for males, migrants, and individuals from wealthy families. The most rank-sensitive individuals attach an almost equal weight to rank and absolute income, implying they would require as much as a 200 per cent increase in income to be compensated for a complete loss of rank (i.e., to move from the top of a small hill to the foot of a big hill).

In terms of reference groups, we find migrants who reside abroad for longer periods of time, and with more affluent job titles, are more likely to compare with others at the destination. Using this information, we introduced a dynamic problem of compensating incomes. Heterogeneity entered this model via; tastes, assimilation, and initial standing within the home society. We used the model to calculate the amount of additional income that a fully rational migrant, with reduced status, required in order to enjoy the same discounted lifetime utility as in the situation where she had not migrated. The average respondent from a low-income society (e.g., Mexico), where the mean income is $\$ 14,000$, required a permanent income increase of 30 per cent (on average) to move to a rich society (e.g., the USA).

Our final interest involved the form of relative income that explains observed choices best. We ran an econometric 'beauty contest' between various measures of income, status, and inequality. Based on the value of the likelihood function, income rank accounted for observed choices best, however ratio comparison income produced an almost identical model fit. Both of these relative income measures predicted choices better than relative deprivation, relative poverty, and income inequality. Thus, we concluded that individuals seem to be pursuing the more simple measures of status.

The survey instrument introduced in this study has enabled us to examine entire income distributions, coupled with the notion of endogenous reference group formation. Despite this richness, using stated-preferences entails some important limitations. Most apparent, what people say they will do is often not the same as what they actually do. Even if participants do respond as if they applied their true utility weights to the attributes presented in the choice experiment, the choice scenarios are quite different from a real-life situation in which migration costs will be non-negligible. These shortcomings, and others, are detailed by Bertrand and Mullainathan (2001), and, more recently, Levitt and List (2007). Additionally, Carlsson et al. (2009) discuss more specific problems in current approaches to measuring relative preferences.

Overall, the notion that people's utility is partially determined by how their income measures up to 
that of others in a society seems to be a settling debate. The form of relative income that individuals relate to is yet to be agreed upon. This issue is important for the policymaker as choice behaviour and social welfare are set to differ under the alternative measures of relative income. For instance, if we consider individuals to be sensitive to income rank instead of ratio comparison income, then there always exists an individual who is placed first and another individual who is placed last, i.e. the overall amount of rank is immutable. This linearity implies no direct role for the re-distribution of income (however, there still may be an indirect role via the effort individuals waste on increasing their rank, see Frank (1985)). On the other hand, if utility depends, in a concave manner, on ratio comparison and average (group) income, then overall utility can be increased via transfers from the rich to the poor, strengthening the case for re-distribution that could be made on the basis of the importance of absolute income for utility. Similarly, as in Frank (1985), it may be possible to observe several rank races, where multiple individuals are led to believe that they occupy first place. Such behaviour is difficult to imagine when individuals care about their position relative to the average in society. 


\section{References}

Ai, C. and Norton, E. (2003) Interaction terms in logit and probit models, Economics Letters, 80, $123-129$.

Aitchison, J., and Brown, J. (1957) The lognormal distribution, with special reference to its uses in economics, Cambridge University Press, Cambridge.

Alpizar, F., Carlsson, F., and Johansson-Stenman, O. (2005) How much do we care about absolute versus relative income and consumption? Journal of Economic Behavior and Organization, 56, 405-21.

Andersson, F. (2008) Is concern for relative concumption a function of relative consumption? Journal of Socio-Economics, 37, 353-364.

Becker, G., Murphy, K., and Werning, I. (2005) The equilibrium distribution of income and the market for status, Journal of Political Economy, 113, 282-310.

Bertrand, M. and Mullainathan, S. (2001) Do people mean what they say? Implications for subjective survey data, American Economic Review, Papers and Proceedings, 91, 67-72.

Bilancini, E., and Boncinelli, L. (2008) Ordinal vs cardinal status: two examples, Economics Letters, 101, 17-19.

Boskin, M. and Sheshinski, E. (1978) Optimal redistributive taxation when individual welfare depends upon relative income, Quarterly Journal of Economics, 92, 589-601.

Brown, G., Gardner, J., Oswald, A., and Qian, J. (2008) Does wage rank affect employees' wellbeing? Industrial Relations, 47, 355-389.

Carlsson, F., Gupta, G., and Johansson-Stenman, O. (2009) Keeping up with the Vaishyas? Caste and relative standing in India, Oxford Economic Papers, 61, 52-73.

Carlsson, F., Johansson-Stenman, O., and Martinsson, P. (2007) Do you enjoy having more than others? Survey evidence of positional goods, Economica, 74, 586-98.

Clark, A., Frijters, P., and Shields, M. (2008a) Relative income, happiness and utility: an explanation for the Easterlin Paradox and other puzzles, Journal of Economic Literature, 46, 95-144.

Clark, A., Kristensen, N., and Westergard-Nielsen, N. (2009) Economic satisfaction and income rank in small neighbourhoods, Journal of the European Economic Association, 7, 519-527.

Clark, A., Masclet, D., and Villeval, M. (2008b) Effort and comparison income, CEP Discussion Paper No. 0886. 
Clark, A. and Senik, C. (2010) Who Compares to Whom? The Anatomy of Income Comparisons in Europe, Economic Journal, 120, 573-594.

Constantinides, G. (1990) Habit formation: A resolution of the equity premium puzzle, Journal of Political Economy, 98, 519-43.

Duesenberry, J. (1949) Income, saving and the theory of consumer behavior, Harvard University Press, Cambridge, MA.

Easterlin, R. (1974) Does economic growth improve the human lot? Some empirical evidence, in David, R. abd Reder, R. (Eds.), Nations and Households in Economic Growth: Essays in Honor of Moses Abramovitz, Academic Press, New York.

Frank, R. (1985) Choosing the Right Pond, Oxford University Press, Oxford.

Frank, R. (1999) Luxury Fever, Free Press, New York.

Frank, R. and Hutchens, R. (1993) Wages, seniority, and the demand for rising consumption profiles, Journal of Economic Behavior and Organization, 21, 251-276.

Friedman, M. and Savage, L. (1948) The utility analysis of choices involving risk, Journal of Political Economy, 56, 279-304.

Gali, J. (1994) Keeping up with the Joneses: Consumption externalities, portfolio choice, and asset prices, Journal of Money, Credit, and Banking, 26, 1-8.

Greene, W. (2010) Testing hypotheses about interaction terms in nonlinear models, Economics Letters, 107, 291-296.

Hopkins, E. and Kornienko, T. (2004) Running to keep in the same place: consumer choice as a game of status, American Economic Review, 94, 1085-107.

Johansson-Stenman, O., Carlsson, F., and Daruvala, D. (2002) Measuring future grandparents' preferences for equality and relative standing, Economic Journal, 112, 362-83.

Kapteyn, A. (1977) A theory of preference formation, unpublished PhD Thesis, Leyden University.

Layard, R. (1980) Human satisfactions and public policy, Economic Journal, 90, 737-50.

Layard, R. (2005) Happiness. Lessons from a New Science, Allen Lane, London.

Levitt, S. and List, J. (2007) What do laboratory experiments measuring social preferences reveal about the real world?, Journal of Economic Perspectives, 21, 153-74. 
Loewenstein, G. and Sicherman, N. (1991) Do workers prefer increasing wage profiles?, Journal of Labor Economics, 9, 67-84.

Luttmer, E. (2005) Neighbors as negatives: relative earnings and well-being, Quarterly Journal of Economics, 120, 963-1002.

Mayer, S. (1997) What money can't buy: family income and children's life chances, Harvard University Press, Cambridge, MA.

McFadden, D. (1974) Conditional logit analysis of qualitative choice behavior, in P. Zarembka (ed.) Frontiers in Econometrics, Academic Press, New York.

Neumark, D. and Postlewaite, A. (1998), Relative income concerns and the rise in married women's employment, Journal of Public Economics, 70, 157-183.

OECD.Stat (2010) GDP per Capita - Data: Breakdown of GDP in its components, http://stats.oecd.org/Index.aspx?DataSetCode=DECOMP, accessed 24 August 2010.

Parducci, A. (1963) Range-frequency compromise in judgement, Psychological Monographs, 77, 1-29.

Pollak, R. (1976) Interdependent preferences, American Economic Review, 66, 309-20.

Postlewaite, A. (1998) The social basis of interdependent preferences, European Economic Review, 42, 779-800.

Robson, A. (1992) Status, the distribution of wealth, private and social attitudes to risk, Econometrica, $60,837-57$.

Runciman, W. (1966) Relative Deprivation and Social Justice, RKP, London.

Sen, A. (1983) Poor, relatively speaking, Oxford Economic Papers, 35, 153-169.

Solnick, S. and Hemenway, D. (1998) Is more always better? A survey on positional concerns, Journal of Economic Behavior and Organization, 37, 373-83.

Stark, O. and Taylor, J. (1991) Migration incentives, migration types: The role of relative deprivation, Economic Journal, 101, 1163-1178.

Stark, O., and Wang, Y. (2005) Towards a theory of self-segregation as a response to relative deprivation: steady-state outcomes and social welfare, in L. Bruni and P. Porta (ed.), Economics and Happiness: Framing the Analysis, Oxford University Press, Oxford.

Train, K. (2003) Discrete Choice Methods with Simulation, Cambridge University Press, Cambridge. 
Train, K., and Wilson, W. (2008) Estimation on stated-preference experiments constructed from revealedpreference choices, Transportation Research Part B: Methodological, 42, 191-203.

Veblen, T. (1899) The Theory of the Leisure Class, [Originally published by Macmillan New York], George Allen and Unwin, London.

Yitzhaki, S. (1979) Relative deprivation and the gini coefficient, Quarterly Journal of Economics, 93, 321-324. 


\section{A Appendix}

\section{A.1 Choice Situations: Survey version 1}

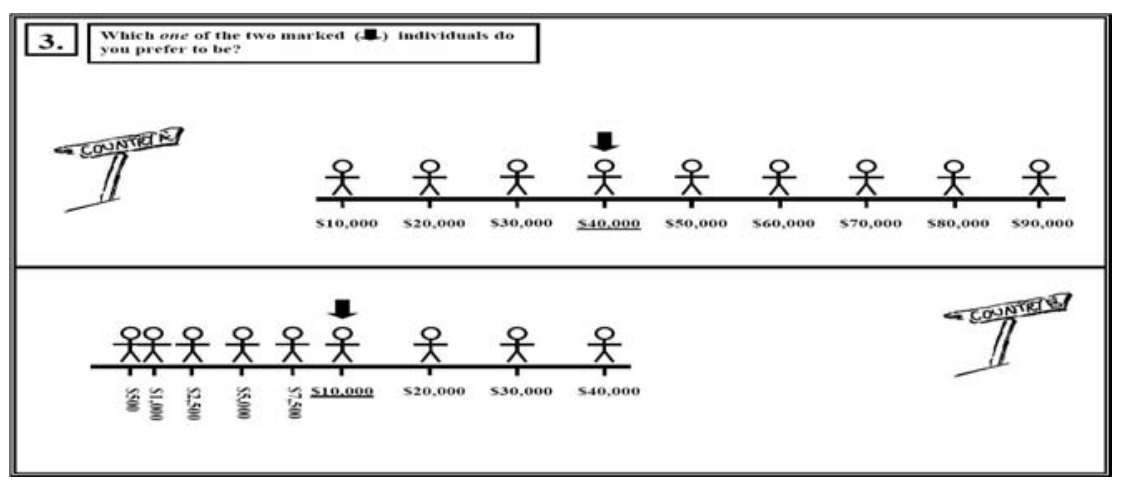

FIG. 9: Choice Situation 3 (Income Rank vs. Absolute Income)

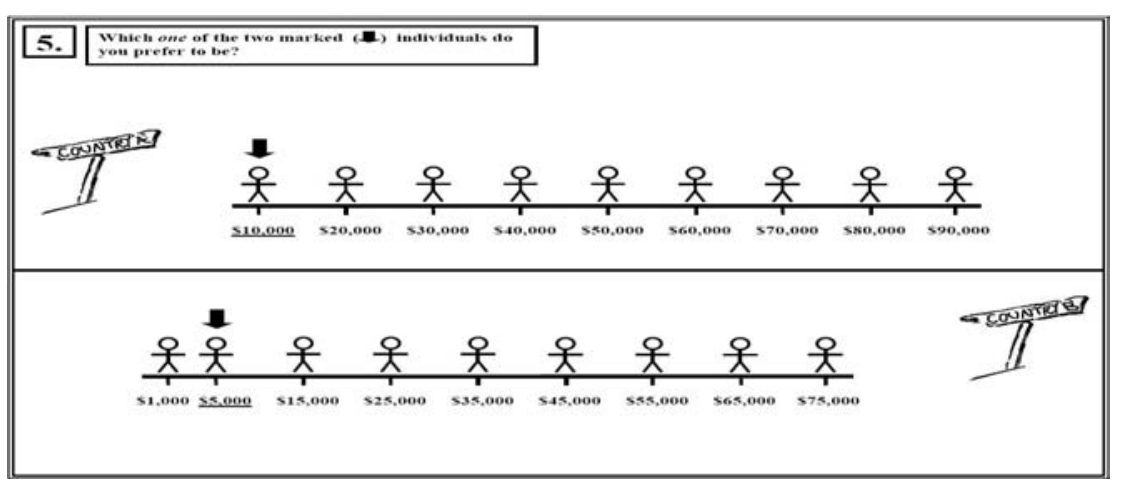

FIG. 10: Choice Situation 5 (Income Rank vs. Absolute Income)

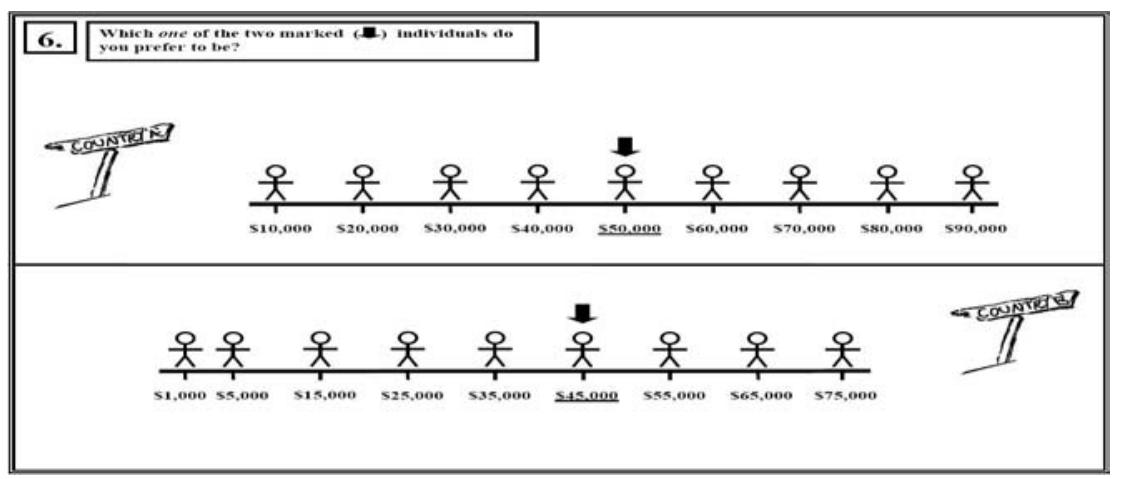

FIG. 11: Choice Situation 6 (Income Rank vs. Absolute Income) 


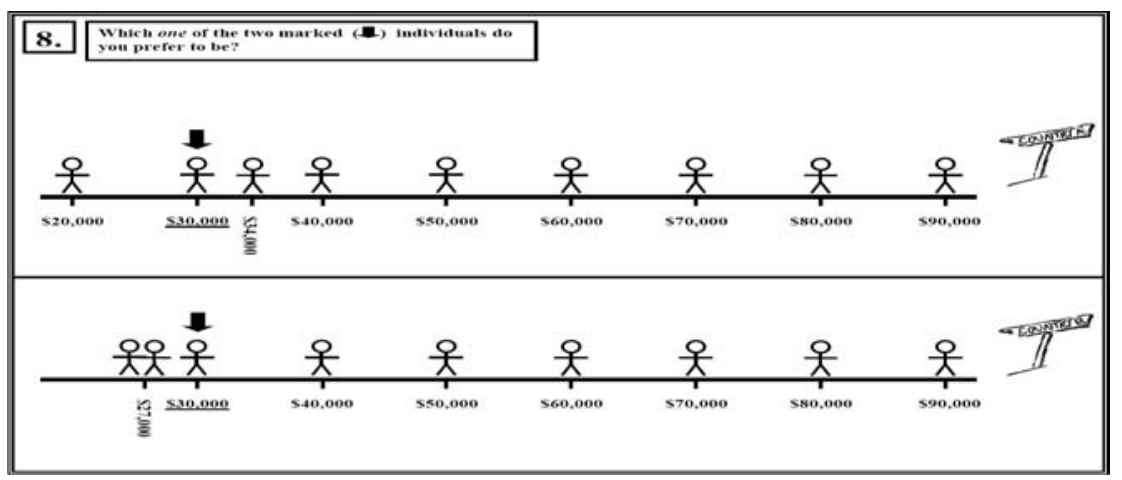

Fig. 12: Choice Situation 8 (Income Rank vs. Ratio Comparison Income)

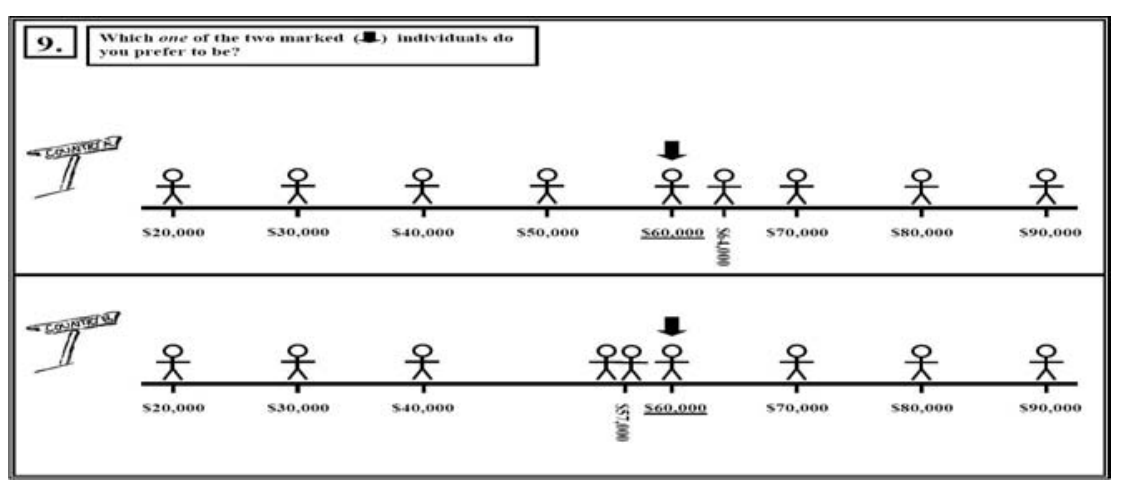

FIG. 13: Choice Situation 9 (Income Rank vs. Ratio Comparison Income)

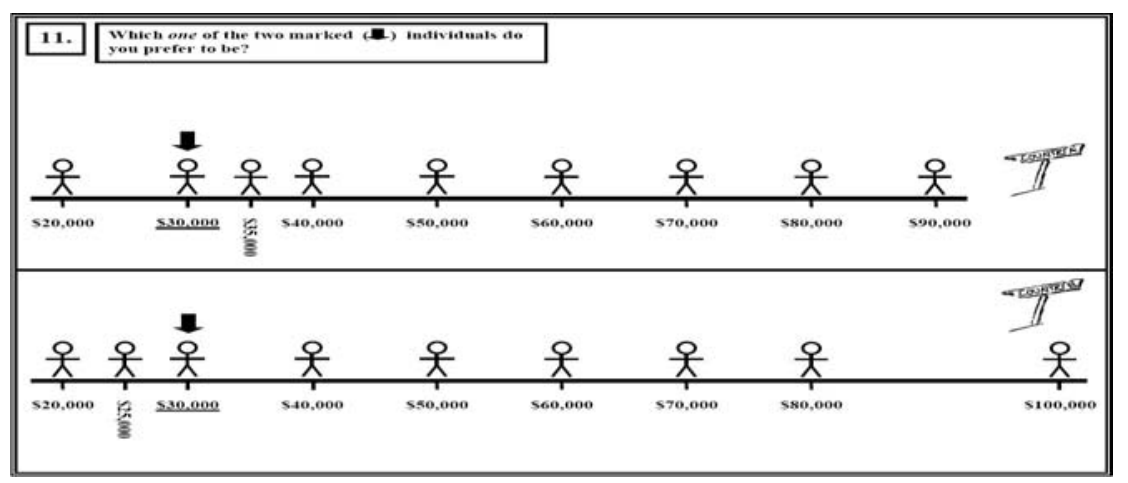

FIG. 14: Choice Situation 11 (Income Rank vs. Relative Deprivation) 


\section{A.2 Choice Situations: Survey version 2}

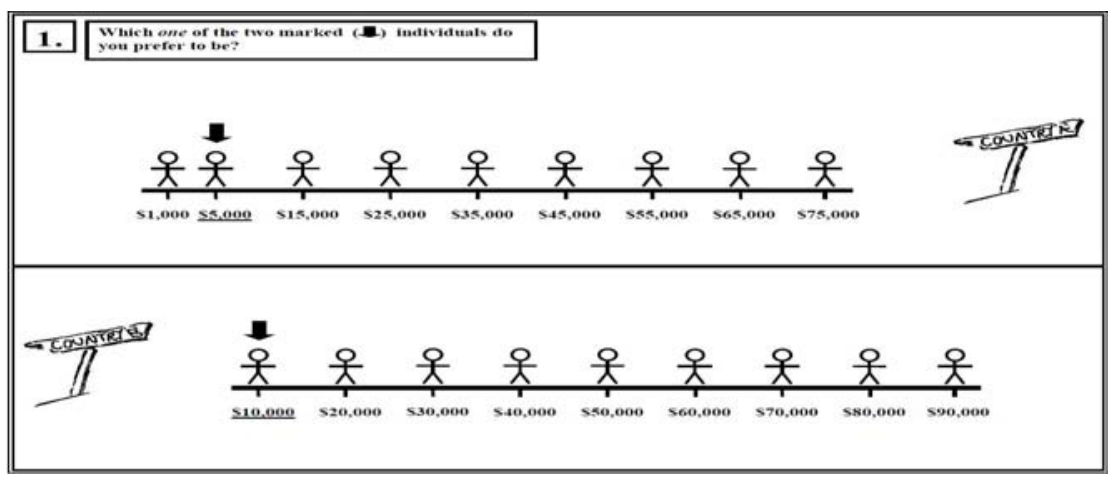

FIG. 15: Choice Situation 1 (Income Rank vs. Absolute Income)

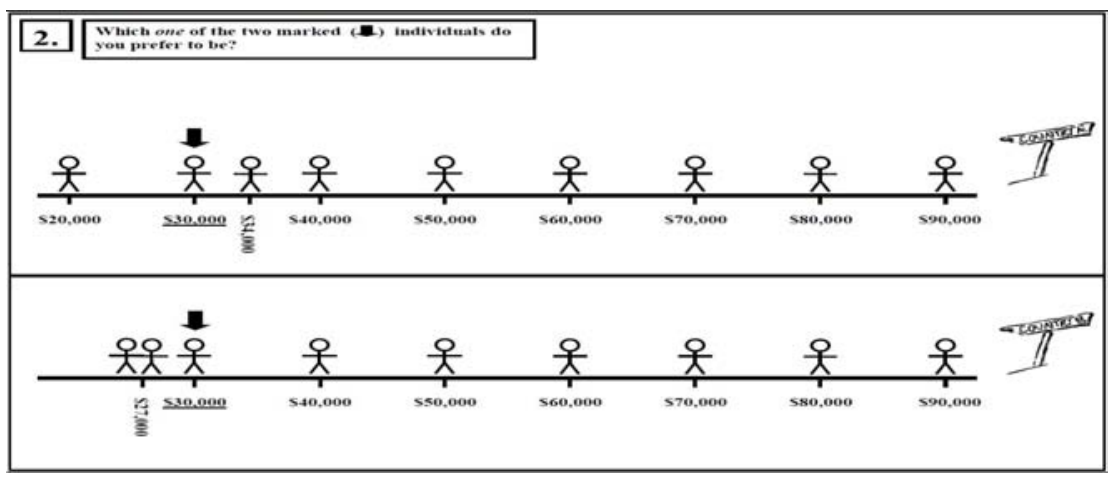

FIG. 16: Choice Situation 2 (Income Rank vs. Ratio Comparison Income)

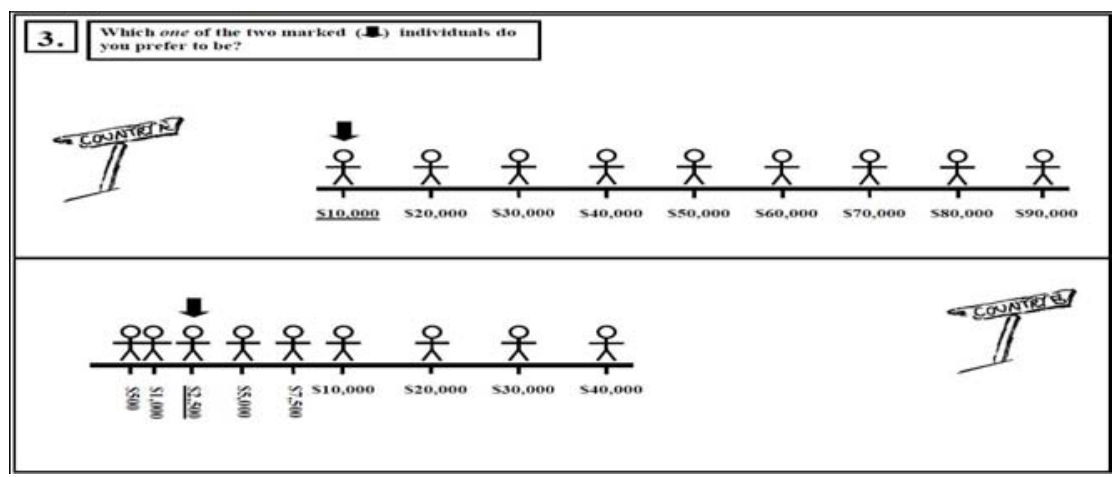

FIG. 17: Choice Situation 3 (Income Rank vs. Absolute Income) 


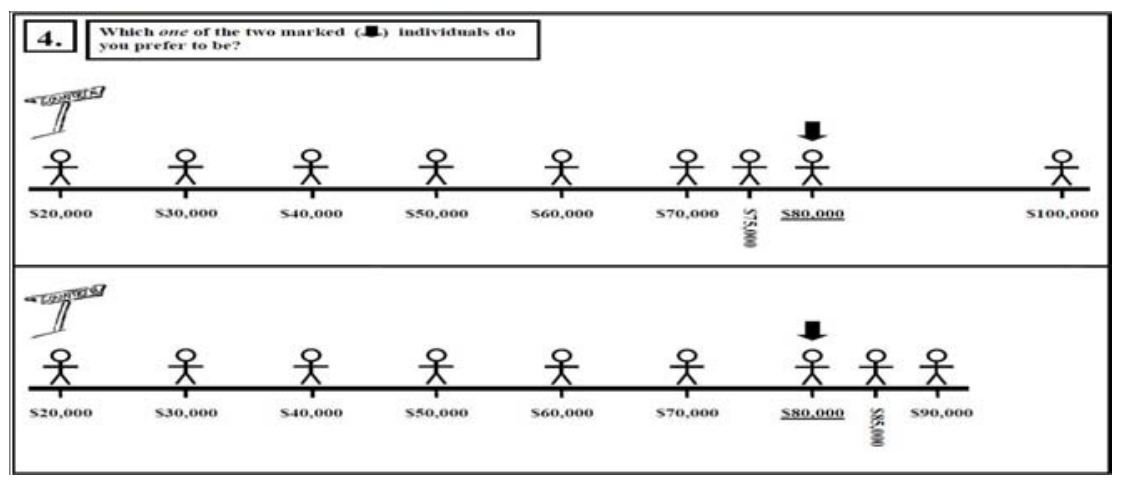

FIG. 18: Choice Situation 4 (Income Rank vs. Relative Deprivation)

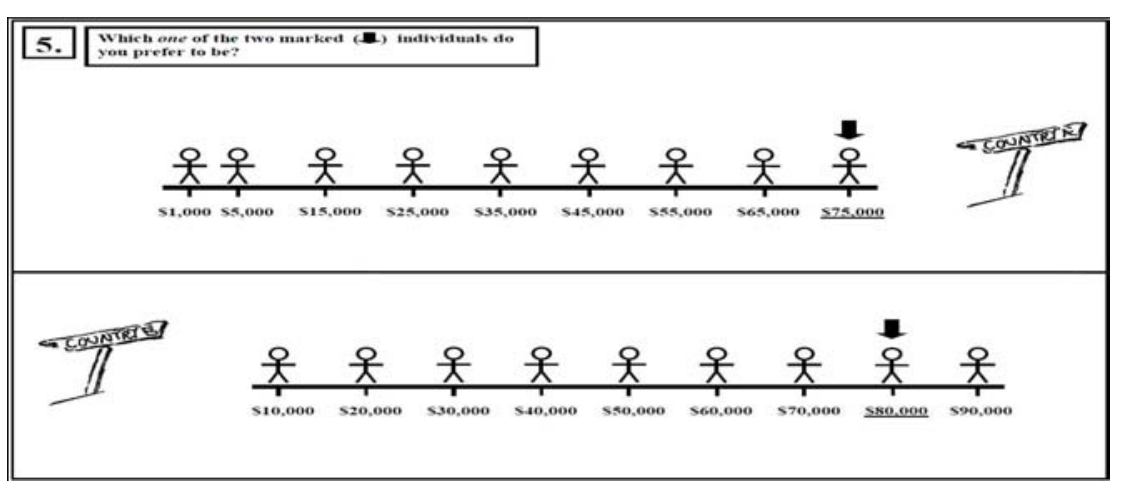

FIG. 19: Choice Situation 5 (Income Rank vs. Absolute Income)

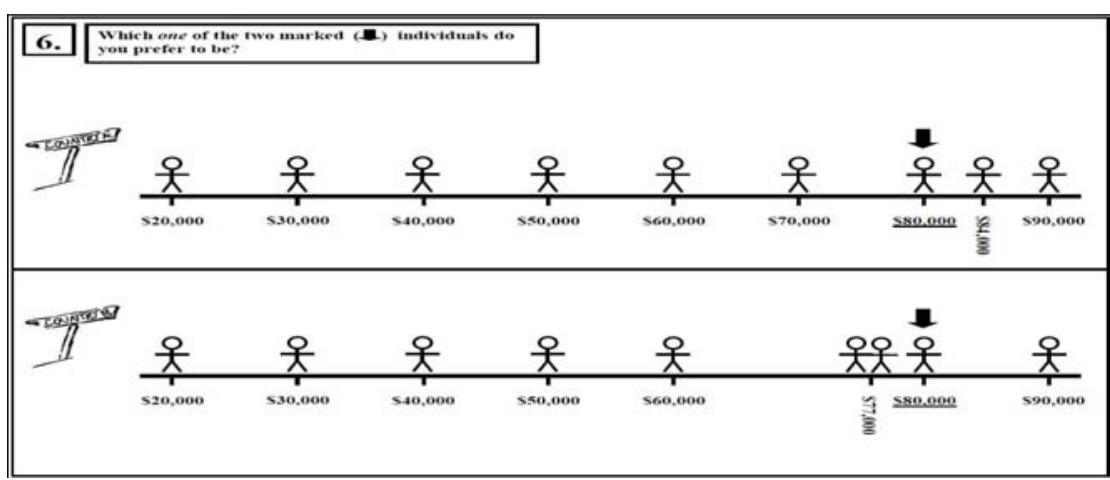

FIG. 20: Choice Situation 6 (Income Rank vs. Ratio Comparison Income) 


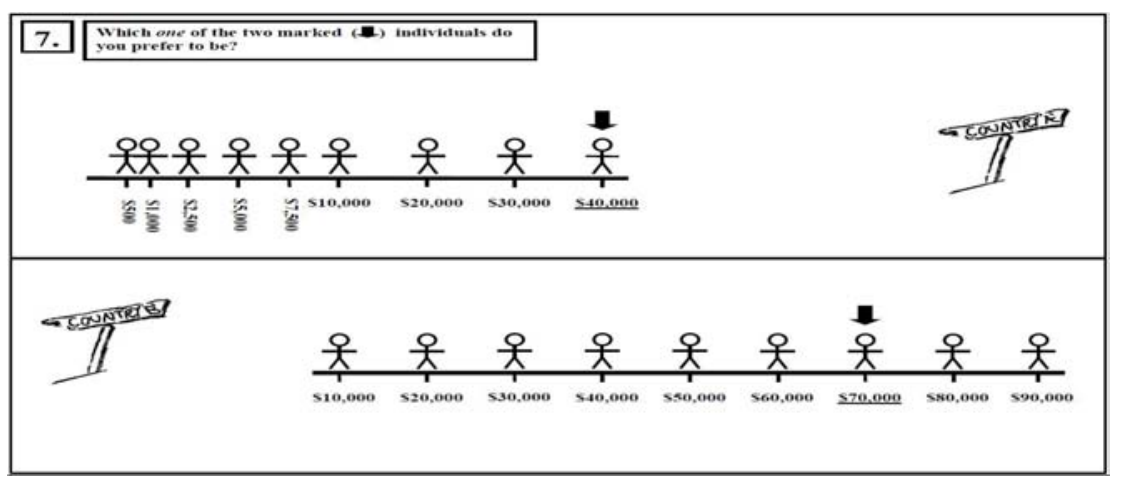

FIG. 21: Choice Situation 7 (Income Rank vs. Absolute Income)

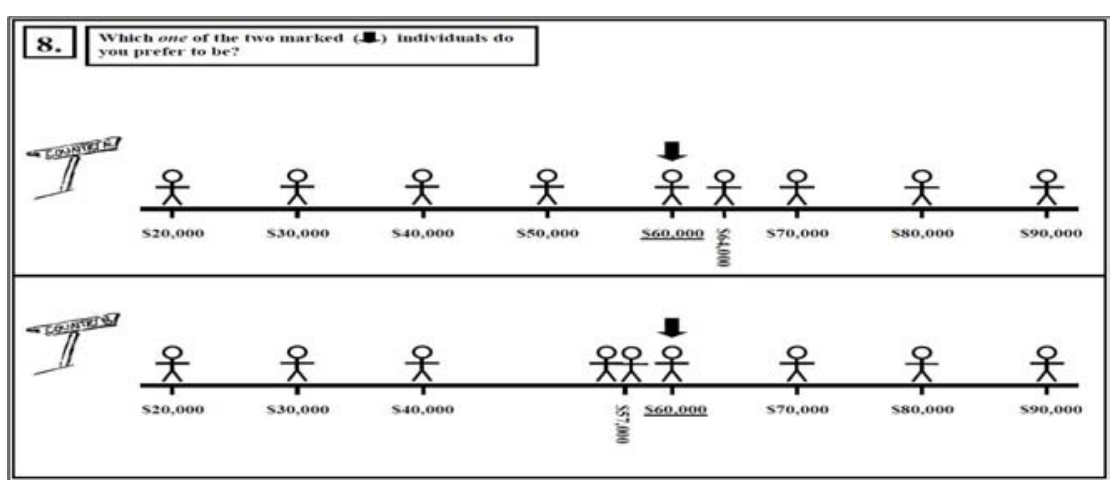

FIG. 22: Choice Situation 8 (Income Rank vs. Ratio Comparison Income)

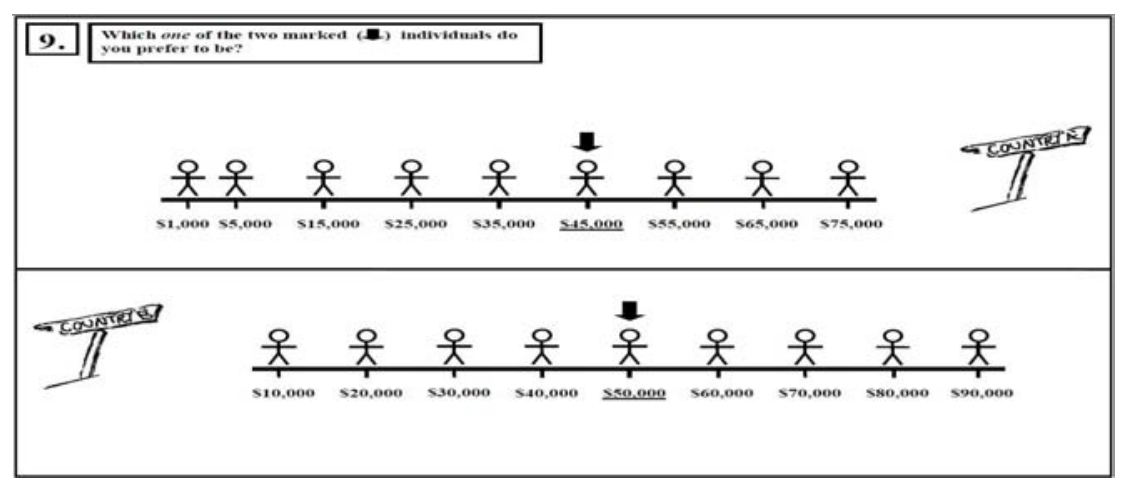

FIG. 23: Choice Situation 9 (Income Rank vs. Absolute Income) 


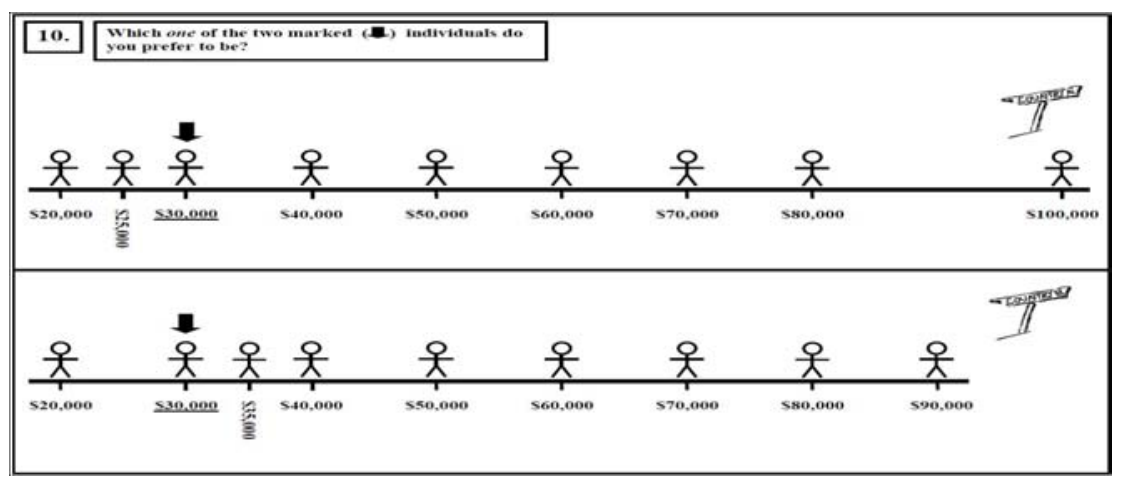

FIG. 24: Choice Situation 10 (Income Rank vs. Relative Deprivation)

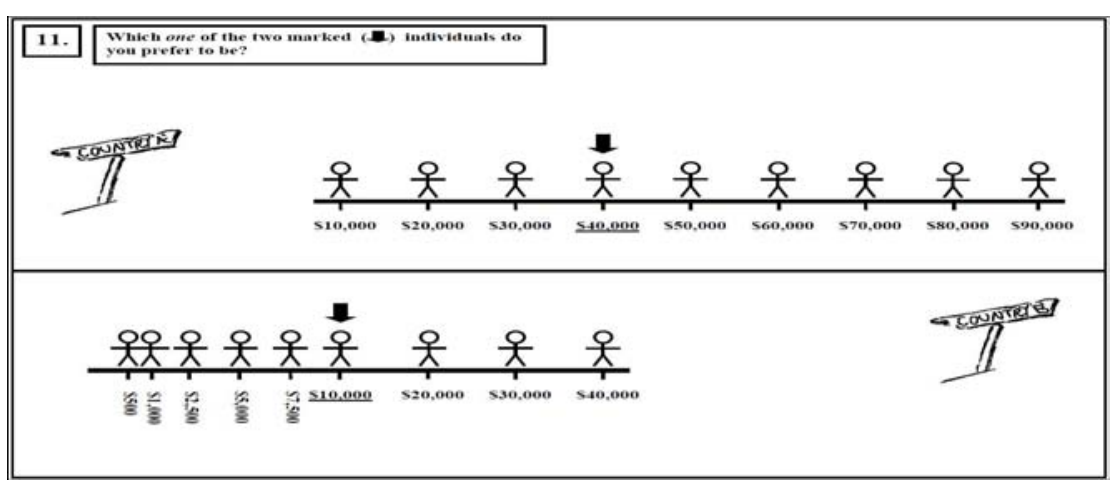

FIG. 25: Choice Situation 11 (Income Rank vs. Absolute Income) 


\section{A.3 Other Summary Statistics and Descriptive Results}

TABle 6: Summary STATistics, FUll SAMPle

\begin{tabular}{lrrrr}
\hline \hline & Mean & Std & Min & Max \\
\hline Age & 22.48 & 5.91 & 16 & 55 \\
Gender & 0.46 & 0.50 & 0 & 1 \\
Partner & 0.29 & 0.45 & 0 & 1 \\
Educated & 0.38 & 0.48 & 0 & 1 \\
Yrs of education & 12.66 & 1.07 & 12 & 15 \\
Employed & 0.70 & 0.46 & 0 & 1 \\
Job title & 1.12 & 1.00 & 0 & 3 \\
Income & 32.10 & 23.38 & 15 & 100 \\
Family wealth & 3.35 & 0.87 & 1 & 5 \\
Migrant & 0.29 & 0.46 & 0 & 1 \\
\hline Number of observations: 1,068 & & & & \\
\hline \hline
\end{tabular}

TABle 7: Summary Statistics, Non-Migrant SUBSAMPle

\begin{tabular}{lrrrr}
\hline \hline & Mean & Std & Min & Max \\
\hline Age & 22.12 & 6.06 & 17 & 55 \\
Gender & 0.43 & 0.50 & 0 & 1 \\
Partner & 0.29 & 0.46 & 0 & 1 \\
Educated & 0.31 & 0.46 & 0 & 1 \\
Yrs of education & 12.49 & 0.92 & 12 & 15 \\
Employed & 0.79 & 0.41 & 0 & 1 \\
Job title & 1.27 & 0.97 & 0 & 3 \\
Income & 31.33 & 23.36 & 15 & 100 \\
Family wealth & 3.42 & 0.85 & 1 & 5 \\
\hline Number of observations: 753 & & & & \\
\hline \hline
\end{tabular}


Table 8: Summary Statistics, Migrant subsample

\begin{tabular}{lrrrr}
\hline \hline & Mean & Std & Min & Max \\
\hline Age & 23.34 & 5.45 & 16 & 52 \\
Gender & 0.52 & 0.50 & 0 & 1 \\
Partner & 0.28 & 0.45 & 0 & 1 \\
Educated & 0.54 & 0.50 & 0 & 1 \\
Yrs of education & 13.08 & 1.27 & 12 & 15 \\
Employed & 0.46 & 0.50 & 0 & 1 \\
Job title & 0.75 & 0.99 & 0 & 3 \\
Income & 33.95 & 23.36 & 15 & 100 \\
Family wealth & 3.18 & 0.90 & 1 & 5 \\
Yrs in Australia & 5.61 & 5.44 & 0 & 28 \\
In contact Home & 0.89 & 0.32 & 0 & 1 \\
Friends in Australia & 0.97 & 0.16 & 0 & 1 \\
Contact, A vs H & 0.71 & 0.45 & 0 & 1 \\
Reference group, A vs H & 0.66 & 0.47 & 0 & 1 \\
\hline Number of observations: 315 & & & & \\
\hline \hline
\end{tabular}

Table 9: Correlation Matrix: Choice Attributes

\begin{tabular}{|c|c|c|c|c|c|c|c|}
\hline & A Abs Income & Income Rank & 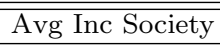 & Std Dev Inc & Ratio Comp Income & Rel Dep & Poverty \\
\hline Abs Income & 1 & & & & & & \\
\hline Income Rank & 0.79 & 1 & & & & & \\
\hline Avg Inc Society & 0.50 & -0.08 & 1 & & & & \\
\hline Std Dev Inc & 0.33 & -0.14 & 0.76 & 1 & & & \\
\hline Ratio Comp Income & 0.65 & 0.88 & -0.15 & -0.18 & 1 & & \\
\hline Rel Dep & -0.76 & -0.93 & 0.11 & 0.27 & -0.77 & 1 & \\
\hline Poverty & -0.43 & 0.11 & -0.91 & -0.52 & 0.16 & -0.09 & 1 \\
\hline
\end{tabular}

NotE: Correlation coefficients between choice attributes for choice situations 1 to 12 , where each choice situation consists of societies A and B. Each attribute vector is of size $(22 \times 1)$, see Table 2 . 
Table 10: Individual Types, Characteristics, \& Preferences

\begin{tabular}{llc}
\hline \hline Individual type & Set of characteristics $\left(X_{i}\right)$ & Pref. parameters $(a, b)$ \\
\hline Reference Individual & $22.48,0,0,0,3.35,0$ & $0.7341,0.0277$ \\
Average Respondent + & $22.48,0,0,1.12,3.35,0$ & $0.7541,0.0417$ \\
Average Respondent $\sigma^{7}$ & $22.48,1,0,1.12,3.35,0$ & $0.8134,0.1930$ \\
Rank-Sensitive (i) & $22.48,1,0,3,5,1$ & $0.9678,0.6248$ \\
Rank-Sensitive (ii) & $40,1,0,3,5,1$ & $0.8178,0.7087$ \\
\hline \hline Migrant type & $22.48,0,0,0,3.35,1$ & $0.7298,0.2132$ \\
\hline Reference Individual & $22.48,0,0,1.12,3.35,1$ & $0.7498,0.2272$ \\
Average Respondent + & $22.48,1,0,1.12,3.35,1$ & $0.8091,0.3785$ \\
Average Respondent $\sigma^{7}$ & $22.48,1,0,3,5,1$ & $0.9678,0.6248$ \\
Rank-Sensitive (i) & $40,1,0,3,5,1$ & $0.8178,0.7087$ \\
\hline Rank-Sensitive (ii) & Note: $X_{i}=[$ Age, Gender, Partner, Job Title, Family Wealth, Migrant]. \\
Definitions and summary statistics of socioeconomic variables are reported in Table 1.
\end{tabular}

